University of Zurich

Department of Economics

Working Paper Series

ISSN 1664-7041 (print)

ISSN 1664-705X (online)

Working Paper No. 296

\title{
Monetary Policy with Imperfect Signals: The Target Problem in a New Monetarist Approach
}

Hannes Draack

August 2018 


\title{
Monetary Policy with Imperfect Signals: The Target Problem in a New Monetarist Approach
}

\author{
Hannes Draack \\ WWZ, University of Basel
}

August 21, 2018

\begin{abstract}
The target problem considers the central bank's use of optimal tools and targets for purposes of stabilization and welfare optimization. In this study, this question is answered anew in a microfounded approach. By adding imperfect information to the model of [Berentsen and Waller, 2011], a divide between an interest rate policy and a money stock policy emerges. Given this, the usefulness of each policy is analyzed, with the ultimate result being the dominance of a pro-cyclical interest rate-based policy. This finding stands in contrast to the well-known macrofounded answer of [Poole, 1970]. The inconsistency is resolved by an examination of some of the axioms underlying New Keynesian and New Monetarist models.
\end{abstract}

JEL Codes E41, E52

Keywords: Money, Search, Stabilization, Monetary Policy 


\section{Contents}

1 Introduction 3

2 Environment 5

3 First-Best Allocation $\quad 9$

4 Agents and Equilibrium Conditions 10

5 The Central Bank's Policy 15

5.1 Policies under perfect information . . . . . . . . . . . . . 16

5.2 Policies without information . . . . . . . . . . . 16

5.2.1 Money Stock Policy without information . . . . . . . . . 18

5.2 .2 Interest Rate Policy without information . . . . . . . 21

5.3 Policy with imperfect information . . . . . . . . . . . . . 25

5.3.1 Money Stock Policy with imperfect information . . . . . . 26

5.3.2 Interest Rate Policy with imperfect information . . . . . . 34

6 Discussion 37

$\begin{array}{lll}7 & \text { Conclusion } & 43\end{array}$ 


\section{Introduction}

The "instrument problem" or "target problem" poses the question, which tools a central bank should use to stabilize and optimize an economy. [Friedman, 1990] provides an overview of the problem and its regarding literature. Whereas New Keynesian approaches to the problem have brought some answers (notably [Poole, 1970], [Sargent and Wallace, 1975]), a New Monetarist perspective on this problem is new. The two primary tools in question are, on the one hand, the supply of money or the money stock, and, on the other hand, the interest rate, at which the central bank offers money via standing facility. New Monetarist research papers to date have used either of these two policies, as most of the time both policies behave equivalently.

Among those following the New Monetarist approach, [Rocheteau et al., 2016] implement an indirect money stock policy through open market operations. [Head et al., 2008] implement an interest rate policy and have banks create inside money. Although these two authors consider that money demand is elastic, the interest rate and money stock are directly related with an injective function. This is also the case in [Berentsen and Waller, 2011], whose model this paper is based upon. Nevertheless, the current research goes further by creating a non-injective function between the interest rate policy and money stock policy, allowing both to be analyzed separately.

The model of [Berentsen and Waller, 2011] is based on the model of [Lagos and Wright, 2005] but is extended by the credit market of [Berentsen et al., 2007] as well as several aggregate shocks that the central bank (CB) can react to with short-term monetary policy. The CB's policy consists of long-term and short-term parts. Long-term, the CB creates a stable inflation rate. This believable and expected price level target allows for short-term influences in the market with monetary injections and retractions, which defines the model's short-term policy. The CB decides the temporary supply of money for a period depending on a received signal regarding the period's aggregate shock. As the central bank is perfectly informed, it knows the interest rate the credit market will settle on. The policy is then regarded as if directly setting the interest rate. The paper finds a pro-cyclical policy to be optimal, and if the Friedman rule is not implemented in the longterm inflation target, the optimal policy makes trade inefficient in all states.

In this current papers model, the central bank only receives an imperfect signal about the aggregate shock. Imperfect Information has been researched 
numerous times in a New Keynesian framework ([Eusepi and Preston, 2018], [Woodford, 2011]). As one example, [Aoki, 2006] uses a forward looking New Keynesian sticky price model where agents have perfect information on the current state, whereas the central bank has to base its policy on noisy information (as is the assumption for this papers model). As [Aoki, 2006] does not divide short-term and long-term policy, the optimal policy corrects earlier mistakes, to stay close to the long-term inflationary target.

This paper uses one aggregate shock to the utility function with two possible states, simulating "high" and "low" aggregate demand for goods. The major addition of the current research is the imperfect signal the $\mathrm{CB}$ receives, resulting in bayesian inference. The discrete nature of the model leads to four different states. The CB either assumes the correct demand for money during a period, or strongly overestimates or underestimates it.

At this stage, in contrast to [Berentsen and Waller, 2011], a divide is created between an interest rate and a money supply policy. If the $\mathrm{CB}$ decides to use monetary injections as in [Berentsen and Waller, 2011] as its short-term stabilizing tool, it uses two different injections, depending on the received signal. Given the actual state, four interest rates are possible to emerge. If, on the other hand, the CB uses a standing facility to offer one of two fixed interest rates, four different stocks of money result.

In this study, three major results are found.

First, as in [Berentsen and Waller, 2011], all optimized policies are procyclical: As demand is high (low), the CB tries to have high (low) money supply and low (high) interest rates. In this regard, New Monetarist (NM) papers usually contradict New Keynesian (NK) models, for example [Poole, 1970]. This is due to the type of optimization chosen for the papers. Poole uses the qualitative equivalent of a squared loss function, as is usually used in NK frameworks ([Sack and Wieland, 2000], [Cecchetti, 2000]), whereas papers based on [Lagos and Wright, 2005], including this one, usually use welfare maximization with a Ramsey function. A comparison of this important and very basic assumption regarding which optimization function to use is discussed by [Woodford, 2010].

Second, the less reliable the signal, the more conservative the policy has to be, with a passive policy at a completely unreliable signal. This is easily intuitively graspable and similar to New Keynesian findings, for example that of [Aoki, 2003].

Third, the interest rate policy always allows for higher welfare than the money stock policy if the signal is imperfect. This stands in stark contrast to 
one of the oldest and most basic papers on this issue, [Poole, 1970], working in a New Keynesian framework. Poole finds the interest rate policy or the monetary policy optimal, depending on the types of shock; for the shock to goods demand, as in this paper, he considers the money stock policy to be optimal.

Another finding, of minor relevance though, is that the zero lower bound of interest is possible to be met in some states under a money stock policy. Given a state of low demand for money, if the CB injects enough money, buyers demand for money can be satisfied, and trades will be efficient in that state. This comes at the price of decreased efficiency in the other states of that economy. Due to the structure of the model, this is not a liquidity trap, a topic analysed in many current papers ([Eggertsson et al., 2003], [?]).

This paper is structured as follows. First, the general environment is defined. From that, a first-best allocation is derived. Then the agents' behaviour is considered and equilibrium conditions are stated. Following that, the different policies of the central bank are analyzed, first with perfect information following [Berentsen and Waller, 2011], then with a completely information-free signal, and lastly in the general case of imperfect information. In the last section, the behaviours and differences of both policies are discussed, and an excursus on [Poole, 1970] shows the importance of a microfounded perspective when analyzing policy.

\section{Environment}

Time is discrete and indexed by $t=1,2, \ldots, \infty$. Each period $t$ is divided into four phases: the information phase (IP), a financial market (FM), a goods market $(\mathrm{GM})$, and a settlement market $(\mathrm{CM})$. This setup is based on [Berentsen and Waller, 2011], with the exception of the IP, which is added for sequential clarity. In the IP, the two types participants in the economy, namely, the economic agents and the central bank $(\mathrm{CB})$, receive information about their respective shocks. In the financial market, agents can borrow and lend money either at a competitive rate or a standing facility, depending on the CB's policy. This market was first implemented in [Berentsen et al., 2007]. In the goods market, agents either produce or consume amounts of the general good, depending on their type. The good is traded at a competitive market price, as in [Rocheteau and Wright, 2005]. This is chosen for simplicity; other bargaining protocols

lead to similar results. The settlement market is a frictionless, centralized mar- 
ket, where all agents can produce and consume the general good, and financial contracts are settled. A timeline is provided in Figure 1.

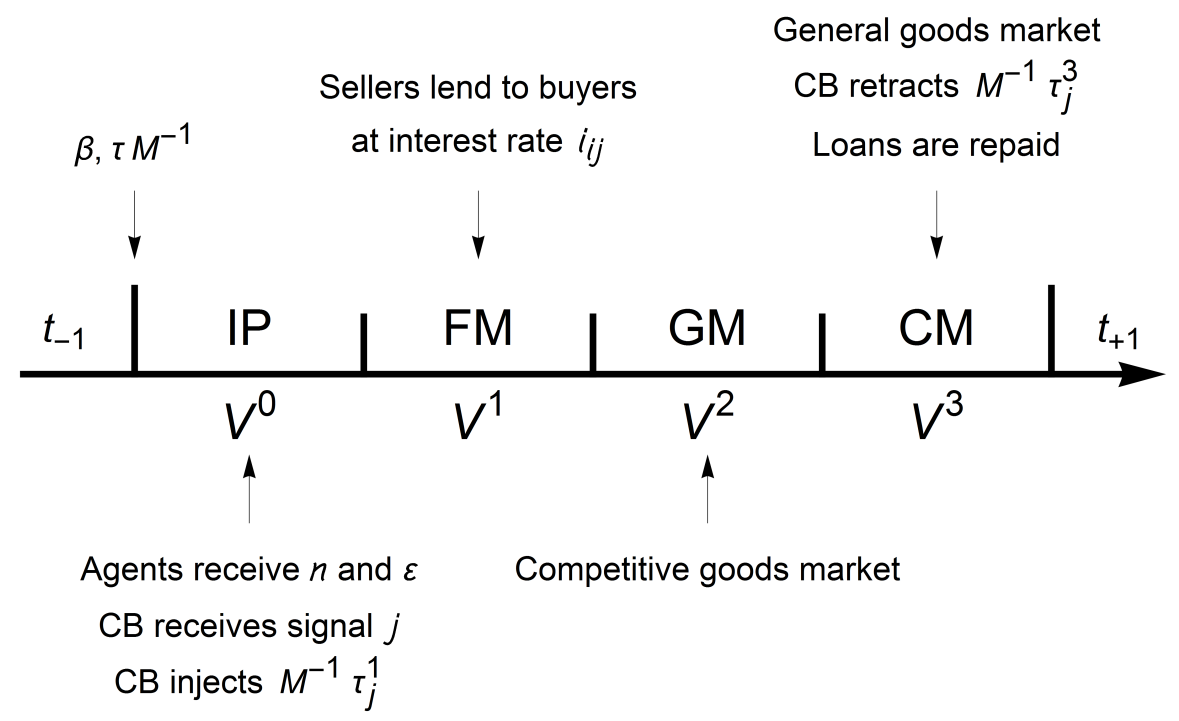

Figure 1: Timeline

The economy is populated by a measure one of infinitely lived agents. At the beginning of each period, an agent is subject to both an aggregate and an idiosyncratic consumption shock. The aggregate consumption shock denotes the agent's desire to consume in the GM, and is described by $\varepsilon_{i}>0$ with $i \in I=(l, h)$ and probabilities $\pi_{l}=1-\pi_{h}$. The idiosyncratic shock determines whether the agent will be a producer or a consumer in the GM. With probability $s$, the agent can produce, but not consume, while with probability $n$, the agent can consume, but not produce. Consumers and producers are refered to as buyers and sellers, respectively; the terms will be used interchangeably. Agents are always either a seller or a buyer, so that $s+n=1$. As a buyer, an agent will enjoy utility $\varepsilon_{j} u(q)$ from consuming $q$ units of the general good in the goods market. As a seller, an agent will suffer disutility $c(q)$ from producing $q$ units of the general good. The utility function of consumption $u(q)$ is twice differentiable and concave. The (dis)utility function of production $c(q)$ is twice differentiable and convex. Utility in the CM is set up as is standard in [Lagos and Wright, 2005] frameworks, so that quasi-linearity ensues. Agents receive $U(x)$ of utility for consuming $x$, with $U^{\prime}(x)>0, U^{\prime}(0)=\infty, U^{\prime}(+\infty)=0$ and $U^{\prime \prime}(x) \leq 0$. Agents' production of $x$ is at the disutility $x$. Given all this, an agents life time 
expected utility is:

$$
E=\sum_{t_{0}}^{\infty} \beta^{t-t 0} \sum_{\omega \in \Omega} \pi_{\omega}\left[U\left(x_{\omega}^{t}\right)-x_{\omega}^{t}+n u\left(q_{b \omega}^{t}\right)-s c\left(q_{s \omega}^{t}\right)\right]
$$

The record keeping technology has to be such that it allows for a credit market between agents and necessitates the use of fiat money at the same time. The precise terms for this setup have been elaborated in [Berentsen et al., 2007]. The paper uses banks as profitless intermediaries with some record keeping technology. Also, it is assumed that agents have this technology to some extent. Specifically, agents are able to uniquely recognize each other in the financial market as well as in the settlement market and commit to and enforce the repayment of loans. This enables a frictionless money market. In contrast, in the GM, agents trade anonymously and have no record keeping technology. Trade credit is not feasible. The general good cannot be stored, hence production and consumption have to happen in the same market. As a single agent can only either produce or consume, the agent has to trade, and the only viable option for trade is the use of fiat money.

Fiat money is brought into the economy by a CB. The CB's monetary policy is divided into a long-term policy and a short-term policy. The long-term goal is to control the inflation rate, while the short-term goal is to maximize consumer welfare. In this model, long-term means over all periods, while short-term means within a single period. As the focus is on steady state equilibria, in the long-term the real money supply is constant, i.e.

$$
\phi_{t}^{3} M_{t}=\phi_{t+1}^{3} M_{t+1}
$$

and evolves according to the following law of motion, $\gamma=M_{t+1} / M_{t}$, where $\gamma$ denotes the gross growth rate of the money supply and $\phi_{t}^{3}$ denotes the value of money in terms of goods in the settlement market. New money is injected $(\gamma>1)$ or withdrawn $(\gamma<1)$ through lump-sum transfers, $T=\tau M$, to each agent in the financial market, where $\tau$ is per-unit-of-money transfer. Hence, the following expression also holds, $\gamma=1+\tau$. This supply of money is not dependent on the period's state or the signal, explained below.

The short-term policy aims to maximize the welfare in a period. The CB has two mutually exclusive options. The first option is a short-term expansion or contraction of the money supply. This option is referred to as the money stock 
policy (MSP) as it directly influences the available money stock. The second option is the implementation of a standing facility, which lends and borrows at a fixed interest rate. In the same fashion, this option is called the interest rate policy (IRP).

The MSP is implemented as in [Berentsen and Waller, 2011]. If the CB elects a MSP, it injects or retracts $T_{j}^{1}=\tau_{j}^{1} M_{t-1}$ in the financial market. This is done with a lump sum to all agents. As in [Berentsen and Waller, 2011], the $\mathrm{CB}$ has to undo this transaction in the settlement market so as not to distort the price level and the long-term inflation rate. Under an MSP, the CB fixes the supply of money, and the interest rate is determined by the market.

If the $\mathrm{CB}$ elects for the IRP, it sets up a standing facility in the financial market with a fixed interest rate. Agents may borrow or lend at this interest rate. Money can be created as it is needed, and the money stock will return to its starting point in the settlement market. As the interest rate is fixed, the money stock is determined by the agents' demand. In [Berentsen and Waller, 2011], both policies are handled equivalently, that is, the CB's injections of money result in the same interest rates as a standing facility would. In this model however, the introduction of imperfect information for the CB creates a divide between the money stock and interest rate policies.

In the information phase (IP), agents receive a perfect signal of the aggregate consumption shock $\varepsilon_{j}$. In contrast, the $\mathrm{CB}$ only receives a signal $\varepsilon_{j}$ with $j \in$ $J=(l, h)$. The probability of receiving the correct signal is $\delta$, the probability of receiving an incorrect signal is $1-\delta$. With $\delta=1$, the model is similar to [Berentsen and Waller, 2011]. In the generalized case with an imperfect signal with $\delta<1$, a period can be in one of four possible states:

\begin{tabular}{l|l|l}
$i j$ & $\delta$ & $1-\delta$ \\
\hline$\pi_{h}$ & $h h$ & $h l$ \\
\hline$\pi_{l}$ & $l l$ & $l h$
\end{tabular}

The variables associated to these states are labelled with the subscript $i j$, where $i=(l, h)$ denotes the true value of $\varepsilon_{i}$ (low or high), while $j=(l, h)$ denote the observation by the CB. For example, the label $h l$ describes the state in which the aggregate consumption shock is $\varepsilon_{h}$, whereas the $\mathrm{CB}$ receives the signal of $\varepsilon_{l}$. The probability of a period being in state $i j$ is denoted by $\pi_{i j}$. In states where $i=j, \pi_{i j}=\pi_{i} \delta$, whereas in states with $i \neq j, \pi_{i j}=\pi_{i}(1-\delta)$. The 
state given as an example above exists with the probability $\pi_{h l}=\pi_{h}(1-\delta)$.

Why does this influence CB policy and create a divide between the MSP and IRP? The answer is in the exact sequence of events. Figure (1) above depicts the four phases of a period. The important detail is in the IP, where the CB receives an inaccurate signal and has to commit to an injection (in the case of a MSP) or to an interest rate (in the case of a IRP). The correct consumption shock could be determined by watching the financial market, at which point though, due to the CB's commitment, a correction of policy is not possible. The important assumption is that the $\mathrm{CB}$ has to decide and commit to its policy before it can derive the actual consumption shock. Assuming a time lag between the CB's short-term decision and the effect on the market is reasonable. Data from markets is always 'old' data: there is always a lag between the collection of data, its evaluation, and the following directive for action.

\section{First-Best Allocation}

The expected lifetime utility of a representative agent at the beginning of period $t$ in a stationary equilibrium is

$$
\begin{aligned}
(1-\beta) W= & U(x)-x \\
& +\pi_{l}\left(n \varepsilon_{l} u\left[q_{l}\right]-s c\left[\frac{n}{s} q_{l}\right]\right) \\
& +\pi_{h}\left(n \varepsilon_{h} u\left[q_{h}\right]-s c\left[\frac{n}{s} q_{h}\right]\right) .
\end{aligned}
$$

The first-best allocation satisfies

$$
U^{\prime}\left(x^{*}\right)=1
$$

and

$$
\begin{aligned}
\varepsilon_{l} u^{\prime}\left[q_{l}^{*}\right] & =c^{\prime}\left[\frac{n}{s} q_{l}^{*}\right] \\
\varepsilon_{h} u^{\prime}\left[q_{h}^{*}\right] & =c^{\prime}\left[\frac{n}{s} q_{h}^{*}\right] .
\end{aligned}
$$

In the first-best allocation information is irrelevant and the economy reduces 
to having two states with $q_{l}^{*}$ and $q_{h}^{*}$ as their efficient quantities.

\section{Agents and Equilibrium Conditions}

Here a given agent's decision in a representative period $t$ is characterized, working backwards from the settlement market to the financial market. In the following section 5 , the solution to the agent's problem is used as the ground for the CB's problem of finding the optimal policy. To simplify the reading, if specification is not necessary, the notation of period or state is omitted.

Settlement market. Let the value function of an agent entering the settlement market with $m$ units of money and $\ell$ units of loan be denoted by $V^{3}(m, \ell)$. Then the agent's problem in the settlement market is

$$
V^{3}(m, \ell)=\max _{x, h, m_{t+1}}\left[U(x)-h+\beta V_{t+1}^{0}\left(m_{t+1}\right)\right]
$$

subject to

$$
x+\phi^{3} m_{t+1} \leq h+\phi^{3}\left(m+T^{3}\right)-\phi^{3}(1+i) \ell
$$

where $\phi^{3}$ is the value of money in units of the general good in this third market (that is, the inverse of the price of a unit of the general good). Under a IRP, $T^{3}$ is zero, as no lump sum has to be repaid. The loan $l$ plus interest is repaid either to other agents or the standing facility, depending on the policy.

An agent in the settlement market maximizes his utility function by choosing consumption of general good, $x$, hours of work, $h$, and the amount of money to bring into the next period, $m_{+1}$, subject to the budget constraint. Note that, as a borrower, the agent has to repay the principal plus interest in the settlement market. This is why the last expression has a negative sign. Also, assuming non-satiation, the budget constraint holds with equality and the above problem can be rewritten as follows:

$$
\begin{aligned}
V^{3}(m, \ell)= & \phi^{3}\left(m+T_{j}^{3}\right)-\phi^{3}(1+i) \ell \\
& +\max _{x, m_{t+1}}\left[U(x)-x-\phi^{3} m_{t+1}+\beta V_{t+1}^{0}\left(m_{t+1}\right)\right]
\end{aligned}
$$

where the budget constraint is used to eliminate $h$ from the objective function. The first order conditions are 


$$
\begin{aligned}
U^{\prime}(x) & =1 \\
\frac{\phi_{t-1}^{3}}{\beta} & =\frac{\partial V^{0}}{\partial m} .
\end{aligned}
$$

Due to the quasi-linearity in consumption, the choice of $m_{+1}$ is independent of $m$ and $\ell$. This simplifies the analysis and is a customary approach as well as a useful feature of the [Lagos and Wright, 2005] framework. The envelope conditions in the settlement market are

$$
\begin{aligned}
& \frac{\partial V^{3}}{\partial m}=\phi^{3} \\
& \frac{\partial V^{3}}{\partial \ell}=-\phi^{3}(1+i) .
\end{aligned}
$$

Goods market. In the goods market, buyers can only consume, while sellers can only produce the general good in this market. The terms of trade in the goods market are determined by competitive pricing. This choice of bargaining protocol does not influence the results of this paper.

First the seller's problem is addressed. Let $V^{2 s}(m, \ell)$ be the value function of a seller entering the goods market with $m$ units of money and $\ell$ units of loan. Then, the seller's problem in the goods market is to choose the amount of goods production, $q^{s}$, that maximizes the lifetime utility, i.e.

$$
V^{2 s}(m, \ell)=\max _{q^{s}}-c\left(q^{s}\right)+V^{3}\left(m+\frac{q^{s}}{\phi^{2}}, \ell\right),
$$

where $\phi_{2}$ denotes the value of money (the inverse of the price of a unit of the general good) in the goods market. The first order condition for a seller in the goods market is

$$
c^{\prime}\left(q^{s}\right)=\frac{\partial V^{3}}{\partial m} \frac{1}{\phi^{2}},
$$

which can be rewritten given (2) as

$$
c^{\prime}\left(q^{s}\right)=\frac{\phi^{3}}{\phi^{2}}
$$


The seller compares the prices on the goods market with the utility to be obtained from the money in the centralized market in order to decide on production. As the seller has no use for money in the goods market, the envelope conditions are

$$
\begin{aligned}
& \frac{\partial V^{2 s}}{\partial m}=\phi^{3} \\
& \frac{\partial V^{2 s}}{\partial \ell}=-\phi^{3}(1+i) .
\end{aligned}
$$

Next the buyer's problem is addressed. Let $V^{2 b}(m, \ell)$ be the value function of a buyer entering the goods market with $m$ units of money and $\ell$ units of loan. Then, the problem in the goods market is

$$
\begin{gathered}
\left.V^{2 b}(m, \ell)=\max _{q^{b}} \varepsilon u\left(q^{b}\right)+V^{3}\left(m-\frac{q^{b}}{\phi^{2}}, \ell\right)\right) \\
\text { s.t. } m-\frac{q^{b}}{\phi^{2}} \geq 0
\end{gathered}
$$

Let $\lambda_{2 b}$ be the Lagrange multiplier on this constraint. A buyer in the goods market decides how much to consume, $q_{b}$, taking the price of the special good $\phi_{2}$ as given, subject to the constraint that the buyer cannot spend more money than the buyer carried into the goods market. Using (2) and (3), the first order condition for a buyer can be rewritten as

$$
\frac{\varepsilon u^{\prime}\left(q^{b}\right)}{c^{\prime}\left(q^{s}\right)}-1=\frac{\lambda^{2 b}}{\phi^{3}}
$$

From (5), consumption is efficient, i.e. $\varepsilon u^{\prime}\left(q^{b}\right)=c^{\prime}\left(q^{s}\right)$, only in case of $\lambda^{2 b}=0$. In this specific case, the buyer's budget constraint does not bind, as he carries more money than the he needs to trade for the efficient quantity $q^{*}$. In contrast, consumption is inefficient, i.e. $\varepsilon u^{\prime}\left(q^{b}\right)>c^{\prime}\left(q^{s}\right)$ if the buyer's cash constraint binds. Finally, the envelope conditions for a buyer in the goods market are

$$
\begin{aligned}
& \frac{\partial V^{2 b}}{\partial m}=\phi^{3}+\lambda^{2 b} \\
& \frac{\partial V^{2 b}}{\partial \ell}=-\phi^{3}(1+i) .
\end{aligned}
$$


Financial market. Entering the financial market, agents have already received all the information about their states and the aggregate state. They know whether they are a buyer or a seller, know the aggregate shock, and know the CB's policy for this period, as they have received either a short-term injection or now see the interest rate at which the standing facility offers credit. Loans can be made either at a market interest rate in the case of a MSP or at the rate the standing facility offers under a IRP. The agent's problem now is to choose how much to borrow $(\ell>0)$ or lend $(\ell<0)$. Given the agent's type $k \in(b, s)$, the agent optimizes

$$
V^{1 k}(m)=\max _{\ell^{k}} V^{2 k}\left(m+\ell^{k}, \ell^{k}\right)
$$

subject to the constraint that the agent cannot lend more money than the agent has, $m+\ell^{k} \geq 0$. Let $\lambda^{1 k}$ be the Lagrange multiplier on this constraint. Note that the CB money injection in the financial market, $T+T_{j}$, is contingent on the signal $j$. The first order condition of the problem above is

$$
\frac{\partial V^{2 k}}{\partial m}+\frac{\partial V^{2 k}}{\partial \ell}+\lambda^{1 k}=0
$$

while the envelope condition is

$$
\frac{\partial V^{1 k}}{\partial m}=\frac{\partial V^{2 k}}{\partial m}+\lambda^{1 k}
$$

Solving the first order condition of the seller in the financial market, the following has to hold:

$$
\lambda^{1 s}=\phi^{3} i
$$

which is at least not negative. If $i>0$, it is easy to show that the seller is lending out all of their money. If $i=0$, the seller is indifferent to lending out money, in which case it is assumed that the lender is willing to do so.

Solving the first order condition for the buyer, as buyers are always net borrowers, the buyer is not constrained by a money holding, thus this results in $\lambda^{1 b}=0$. Then it follows that for the buyer, 


$$
\phi^{3} i=\lambda^{2 b}
$$

which states that the buyer adjusts future consumption to the interest rate found in the financial market, be it from a standing facility or a market rate. As consumption is only efficient when $\lambda_{2 b}=0$, from (7) it is clear to see that consumption in a period can only be efficient if the buyers cash constraint is not binding with $i=0$.

Information Phase. While agents face no decision problem in the information phase, still it is useful to separate it from the other markets for clarity. Agents enter the period with their money holdings coming out of the foregoing period. They receive the knowledge of their type and this period's aggregate demand shock. The CB transfers the lump sum $T$ to them, which, to recall, implements the exogenous long-term growth of the money stock. Depending on the CB's chosen policy and signal received, agents may receive the short-term lump sum injection $T_{j}^{1}$; otherwise the interest rate of the standing facility is decided and announced. The expected utility of an agent entering a new period with money holdings $m$ is

$$
V^{0}(m)=\sum_{i \in I} \sum_{j \in J} \pi_{i j}\left[n V_{i j}^{1 b}\left(m+T+T_{j}^{1}\right)+s V_{i j}^{1 s}\left(m+T+T_{j}^{1}\right)\right] .
$$

The envelope condition entering a new period is

$$
\frac{\partial V^{0}}{\partial m}=\sum_{i \in I} \sum_{j \in J} \pi_{i j}\left[n \frac{\partial V_{i j}^{1 b}}{\partial m}+s \frac{\partial V_{i j}^{1 s}}{\partial m}\right] .
$$

Steady State Equilibrium. It is evident that the agent's choice above depends on the state of the economy, $i j$. The following identifies the market clearing conditions for a steady state equilibrium. Since there is an equal number of buyers and sellers, clearing conditions in the goods market imply that in each state the produced and consumed aggregate quantities of sellers and buyers, respectively, are equal, i.e.

$$
n q_{i j}^{b}=s q_{i j}^{s}
$$

The clearing condition in the financial market requires that the total loans 
and total borrowings are equal in their respective states:

$$
n \ell_{i j}^{b}=-s \ell_{i j}^{s}
$$

At this point the marginal value of money can be derived. Updating $V_{0}^{m}$ one period and using (1), (4), (5), (7) and (8), the equilibrium condition of clearing the settlement market holds:

$$
\frac{\gamma-\beta}{\beta}=\sum_{i \in I} \sum_{j \in J} \pi_{i j}\left[\frac{s}{n} \frac{\varepsilon u^{\prime}\left(q_{i j}\right)}{c^{\prime}\left(\frac{n}{s} q_{i j}\right)}-1\right] .
$$

(9) simply states that the holding cost of money on the left hand side of the equation has to equal the marginal expected utility of carrying money. The interest rate of a state in relation to the produced and consumed goods is

$$
i_{i j}=\frac{s}{n} \frac{\varepsilon u^{\prime}\left(q^{b}{ }_{i j}\right)}{c^{\prime}\left(\frac{n}{s} q^{s}{ }_{i j}\right)}-1
$$

where with $i_{i j}=0$ the economy in that state is efficient with $\frac{s}{n} \frac{\varepsilon u^{\prime}\left(q^{b}{ }_{i j}\right)}{c^{\prime}\left(\frac{n}{s} q^{s}{ }_{i j}\right)}=1$, and with $i_{i j}>0$ the economy in that state is inefficient with $\frac{s}{n} \frac{\varepsilon u^{\prime}\left(q^{b}{ }_{i j}\right)}{c^{\prime}\left(\frac{n}{s} q^{s}{ }_{i j}\right)}>1$. Knowing this, one can see the close relation of (9) to the Fisher equation, as the equilibrium condition can be rewritten as

$$
\frac{\gamma}{\beta}=i_{3}=\sum_{i \in I} \sum_{j \in J} \pi_{i j} i_{i j}
$$

From (10) it is possible to deduce that as long as the Friedman rule is not implemented in the long-term inflation policy, the expected interest rate is always positive, so that the economy will not run efficiently in all states. It is possible though, as is shown below, that the economy may run efficiently in some states of an equilibrium. The efficiency of one state, though, comes at the cost of the higher inefficiency of another state of the same equilibrium. In the next section, this problem will be analyzed in the CB's policy problem.

\section{The Central Bank's Policy}

In this section, the optimal policies for the CB are analyzed. First, the case of perfect information is discussed, then the case with an uninformative signal is covered, and lastly the general case of imperfect information. 


\subsection{Policies under perfect information}

The goal of the CB's short-term policy is to maximize aggregate expected welfare. The expected welfare of a representative period is given by

$$
W(1-\beta)=U(x)-x+\sum_{i \in I} \sum_{j \in J} \pi_{i j}\left[n \varepsilon_{i} u\left(q_{i j}\right)-s c\left(\frac{n}{s} q_{i j}\right)\right]
$$

Having perfect information reduces the economy's equilibria to two states $(l, h)$. This economy would be equivalent to that of [Berentsen and Waller, 2011] with discrete states and fewer shocks. The IRP and the MSP lead to the same Ramsey problem and thus the same equilibrium:

$$
\begin{gathered}
\max _{x, q_{h}, q_{l}} U(x)-x+\pi_{l}\left[n \varepsilon_{l} u\left(q_{l}\right)-s c\left(\frac{n}{s} q_{l}\right)\right]+\pi_{h}\left[n \varepsilon_{h} u\left(q_{h}\right)-s c\left(\frac{n}{s} q_{h}\right)\right] \\
\text { s.t. } \\
\frac{\gamma-\beta}{\beta}=\pi_{l}\left[\frac{s}{n} \frac{\varepsilon u^{\prime}\left(q_{l}\right)}{c^{\prime}\left(\frac{n}{s} q_{l}\right)}-1\right]+\pi_{h}\left[\frac{s}{n} \frac{\varepsilon u^{\prime}\left(q_{h}\right)}{c^{\prime}\left(\frac{n}{s} q_{h}\right)}-1\right]
\end{gathered}
$$

As is stated in [Berentsen and Waller, 2011], as long as the Friedman Rule is not implemented, consumption in all states is inefficient. The optimal policy is pro-cyclical: in states with high productivity, consumption is high and the interest rate is kept low, to support the economy's output, and vice versa.

Figures (2) and (3) show the consumption and interest rates for equilibria with differing inflation rates. It is important to observe that optimally $i_{l}>$ $i_{3}>i_{h}$, which is a pro-cyclical policy. Also, having the same interest rate in all states is not the optimal solution.

\subsection{Policies without information}

One result of this model's add-on of imperfect information to the model of [Berentsen and Waller, 2011] is the disconnect between the short-term money stock and the interest rate. A policy that sets the available money stock depending on the shock behaves differently from a policy that fixes the interest rate in a state. The CB has to decide which of these two policies to implement. 


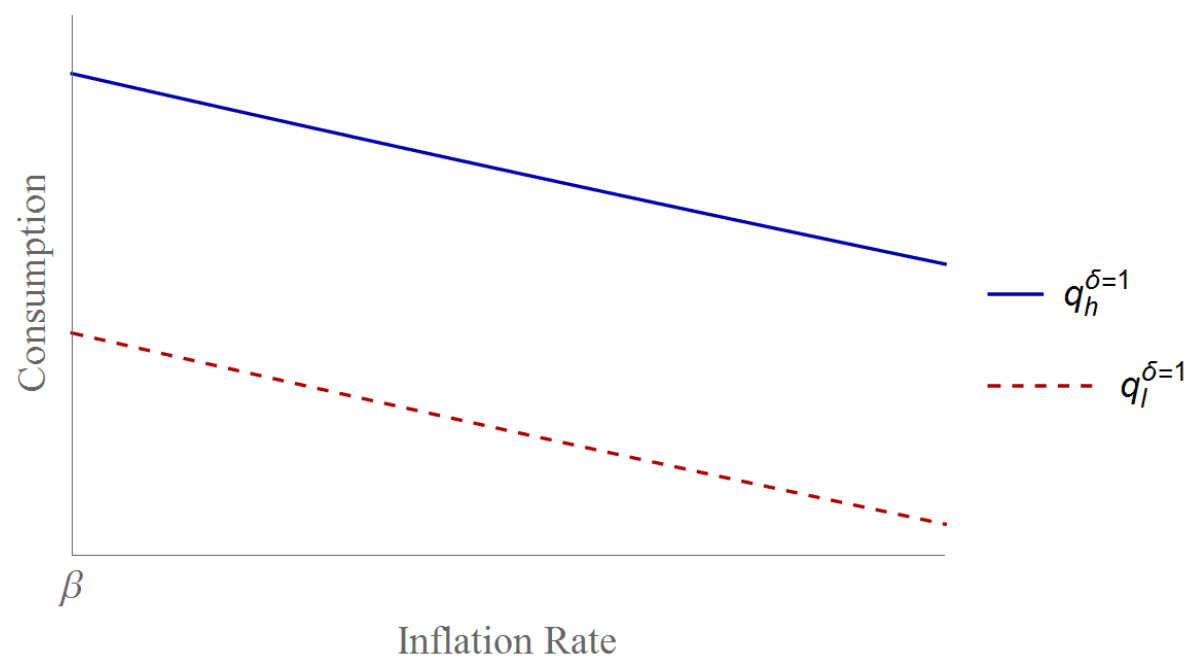

Figure 2: Optimal policy with perfect signal, consumption over inflation

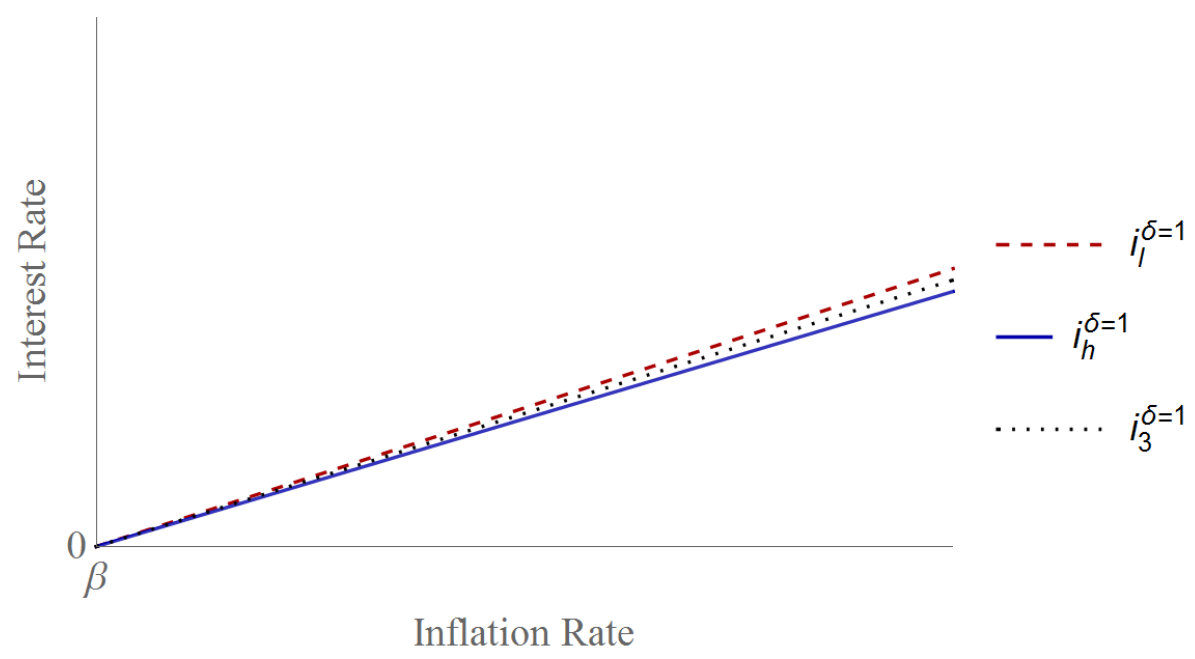

Figure 3: Optimal policy with perfect signal, interest over inflation 
Before looking at the general model, another useful simplification is the reduction given by $\delta=0.5$, at which point the signal carries no information. With this simplification, the difference between the MSP and IRP is clearly observable. The following sections set up the Ramsey problem and resulting equilibria as well as the welfare implications of first the MSP and then the IRP.

\subsubsection{Money Stock Policy without information}

Under a MSP, the CB injects or withdraws signal-contingent money transfers, $T_{j}$ to all agents in the financial market. These transfers are undone in the settlement market. Therefore the money stock - the available liquidity of agents - is fixed, whereas the interest rate is determined endogenously for each state.

As the signal carries no information, the model reduces to having two states $(l, h)$. The CB's policy decision cannot depend on the signal. Thus the injection is the same in any state, and agents carry the same amount of money $m$ into the goods market in both states. 9 reduces to

$$
\frac{\gamma-\beta}{\beta}=\pi_{h}\left[\frac{s}{n} \frac{\varepsilon_{h} u^{\prime}\left(q_{h}\right)}{c^{\prime}\left(q_{h}\right)}-1\right]+\pi_{l}\left[\frac{s}{n} \frac{\varepsilon_{l} u^{\prime}\left(q_{l}\right)}{c^{\prime}\left(\frac{n}{s} q_{l}\right)}-1\right] .
$$

As the injection has to be the same in any state, there exists the following constraint for equilibria:

$$
q_{l}=\left\{\begin{array}{l}
q_{h} \\
q_{l}^{*}
\end{array}\right\} \text { if } q_{h}\left\{\begin{array}{l}
<q_{l}^{*} \\
\geq q_{l}^{*}
\end{array}\right\}
$$

The second constraint (12) has an unusual form. It is not simply $q_{l}<q_{l}^{*}$, which is a constraint of the usual form as found in Lagrange optimization, but rather a discrete form: $q_{l}=q_{h}$ unless $q_{h}>q_{l}^{*}$, in which case $q_{l}=q_{l}^{s}$. While the $\mathrm{CB}$ has the 'freedom' to maximize welfare in the Ramsey problem of 5.1, here the second constraint allows only one unique equilibrium for a given economy, thus the CB can not influence the market after selecting a MSP. Analytically, an equilibrium is defined by the two variables $q_{h}$ and $q_{l}$. While in 5.1 only one constraint allows for maximization over the other variable, here they are defined by the two constraints. From (12) follow two types of equilibria:

Type I equilibrium. In a Type I equilibrium, consumption in all states is inefficient and $\lambda_{i j}>0$ for all $i, j$. In this equilibrium, consumption is such that 
$q_{l}=q_{h}$.

Definition 1 A Type I equilibrium is a path $\left\{q_{l}, q_{h}\right\}$ satisfying (11) and $q_{l}=$ $q_{h}<q_{l}^{*}$.

Type II equilibrium. In a Type II equilibrium, consumption is inefficient in the state with $\varepsilon_{h}$ and efficient with $\varepsilon_{l}$. In this equilibrium, consumption is such that $q_{l}=q_{l}^{*}<q_{h}$.

Definition 2 A Type II equilibrium is a path $\left\{q_{l}, q_{h}\right\}$ satisfying (11), $q_{l}=q_{l}^{*}$ and $q_{h}>q_{l}^{*}$.

In the Type II equilibrium, in states with $\varepsilon_{l}$, buyers carry more money into the GM than they spend. One might say buyers 'save' the money to carry it into the next market.

Proposition 1 Given no information and a MSP, for any set of exogenous variables, there exists a single steady state equilibrium of either Type I or Type II.

Which equilibrium an economy is found in is solely determined by the exogenous variables. Assuming for example the utility functions $u(q)=\frac{q^{0.5}}{0.5}$ and $c(q)=q$, one can solve for the consumption quantities $q_{l}^{*}$ and $q_{h}$, and the following statement can be derived. The economy is of Type I (Type II) if

$$
\frac{\beta}{\gamma}\left(\varepsilon_{l} \pi_{l}+\varepsilon_{h} \pi_{h}\right)<(\geq) \varepsilon_{l}
$$

A higher cost of holding money, either from time preference or inflation, reduces efficiency, and 'shifts' the economy more in the direction of Type I. A higher difference between $\varepsilon_{h}$ and $\varepsilon_{l}$ or a higher probability $\pi_{h}$ shifts the economy to a Type II equilibrium. Both statements are intuitively graspable. As carrying money becomes more costly, the aforementioned 'saving' of buyers becomes more inefficient, so that buyers optimally carry less money and are less likely to meet the efficient quantity in $\varepsilon_{l}$. The other relation uses a similar mechanism: as the likelihood and/or gain from a high state increases, buyers increase their spending power.

Figure 4 presents the consumption quantities of economies with differing rates of inflation. With low inflation, buyers carry more money into the GM 


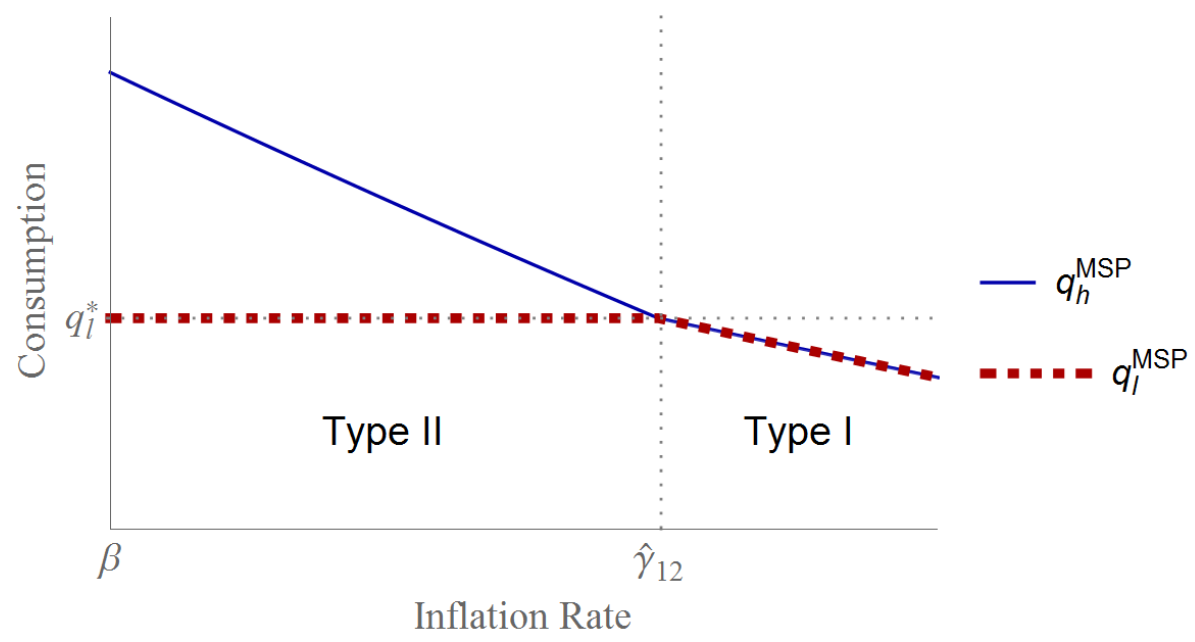

Figure 4: MSP at $\delta=0.5$, consumption over inflation

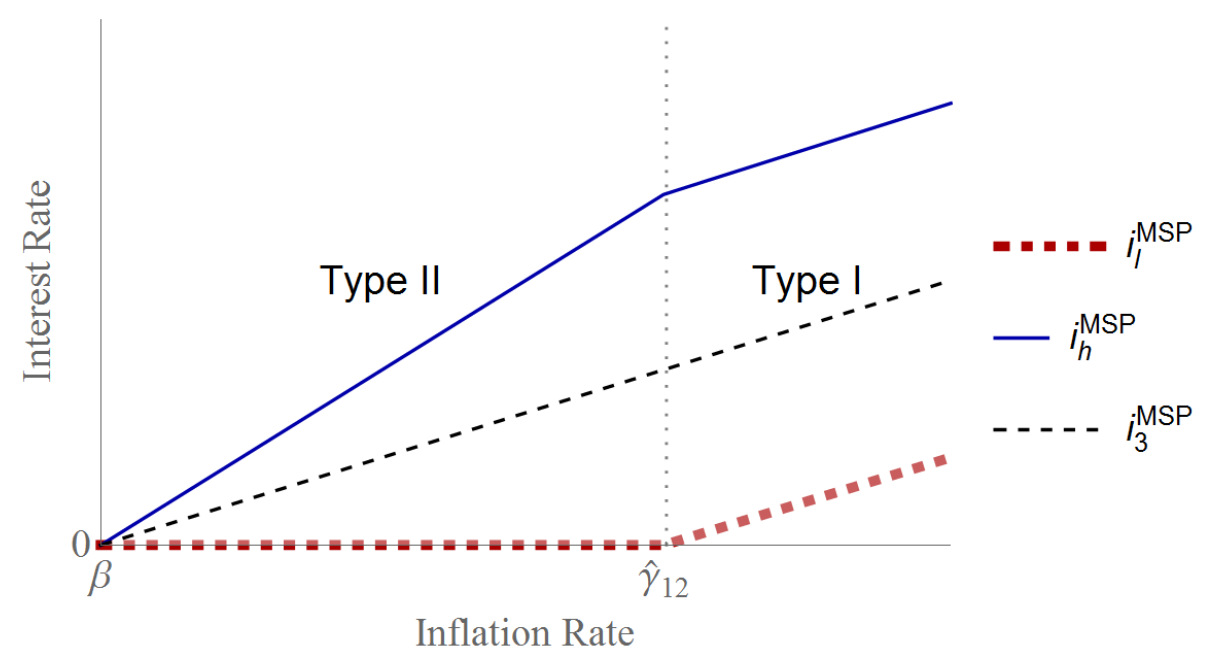

Figure 5: MSP at $\delta=0.5$, interest rate over inflation 
and are thus able to purchase the efficient quantity $q_{l}^{*}$ in states with $\varepsilon_{l}$. The equilibrium of these economies is of Type II. With high inflation, consumed quantities are the same for both states, and the economies are found in Type I equilibria.

Figure 5 shows the corresponding interest rates of the economies. The interest rates centre around $i_{3}$, the cost of holding money. In Type I equilibria, both interest rates are positive, while the interest rate in high productivity states is high due to the high demand for money, and vice versa. In Type II equilibria with low consumption, the zero lower bound of interest rates is met: consumption in some states is optimal, thus demand for additional money is zero.

\subsubsection{Interest Rate Policy without information}

With a IRP, instead of controlling the money stock, the CB sets an interest rate after receiving its information about the current shock. This can be regarded as a standing facility, which exists over the course of one period. The interest rate at which it lends and borrows has to be decided by the CB in the information period, so that it can not react to the agents' actual demand. The publicly known policy consists of the two interest rates $\left\{i_{l}, i_{h}\right\}$. Given the signal $l$ or $h$, the $\mathrm{CB}$ sets rate $i_{l}$ or $i_{h}$ for the period. In the FM, agents would be able to borrow or deposit at that rate and repay the loan in the centralized market at the end of the period. Under the IRP, interests are fixed, and the available money stock is fluid.

Equation (9) still has to hold, so that money has value. This can be proven with the following thought experiment. If the CB's policy were to diverge from (9), the value of money would either be zero or infinity. Imagine these two cases: if the average interest rate $\sum_{i \in I} \sum_{j \in J} \pi_{i j}\left(1+i_{i j}\right)$ of the policy is lower than $\frac{\gamma-\beta}{\beta}$, then carrying money over to the next period would be costlier than simply borrowing from the CB. The demand for money in the CM would be zero, thus money would not have value, and no trade would happen in the GM. In the

other case, suppose $\sum_{i \in I} \sum_{j \in J} \pi_{i j}\left(1+i_{i j}\right)>\frac{\gamma-\beta}{\beta}$. The demand for money would be infinite, as each unit of money for an agent would reap the benefit of the interest rate on it. Thus, the only option is for the CB to set a publicly-known 
policy $\left(i_{l}, i_{h}\right)$ which satisfies 9 . The consumption in a state can be sufficiently described by the $q_{i j}$ that satisfies

$$
i_{i j}=\frac{s}{n} \frac{\varepsilon_{i} u^{\prime}\left(q_{i j}\right)}{c^{\prime}\left(\frac{n}{s} q_{i j}\right)}-1
$$

In the case of $i_{\omega}=0, \frac{s}{n} \varepsilon u^{\prime}\left(q_{\omega}\right)=1$ so that $q_{\omega}=q_{\omega}^{*}$. A negative interest rate would result in overconsumption by the buyers, and no money being lent out by the sellers.

After electing to implement a IRP, the CB chooses interest rates for a standing facility, depending on its received signal. Similar to the reduction above, as the signal carries no information, the CB can implement only one interest rate. In consumption quantities, the problem under a IRP can be stated as follows.

$$
\begin{gathered}
\frac{\gamma-\beta}{\beta}=\pi_{h}\left[\frac{s}{n} \frac{\varepsilon_{h} u^{\prime}\left(q_{h}\right)}{c^{\prime}\left(q_{h}\right)}-1\right]+\pi_{l}\left[\frac{s}{n} \frac{\varepsilon_{l} u^{\prime}\left(q_{l}\right)}{c^{\prime}\left(\frac{n}{s} q_{l}\right)}-1\right] \\
\varepsilon_{l} \frac{u^{\prime}\left(q_{l}\right)}{c^{\prime}\left(\frac{n}{s} q_{l}\right)}=\varepsilon_{h} \frac{u^{\prime}\left(q_{h}\right)}{c^{\prime}\left(\frac{n}{s} q_{h}\right)}
\end{gathered}
$$

While (14) is the same as (12), the difference lies in the second constraint. As interest rates have to be equal in both states, the statement (15) can be made relating the consumption quantities to each other.

$$
\frac{\gamma}{\beta}=i_{3}=\left(\pi_{l}+\pi_{h}\right) i=i
$$

Steady state demands that the standing facility's interest rate satisfies the Fisher equation with $i=i_{3}=\frac{\gamma}{\beta}$. Unless the Friedman rule is implemented in the longrun, the interest rate has to be positive, meaning that consumption is always suboptimal. There exists only one type of equilibrium.

IRP equilibrium. In a IRP equilibrium, consumption in all states is inefficient.

Definition 3 A IRP equilibrium is a path $\left\{q_{l}, q_{h}\right\}$ satisfying (14) and (15). 


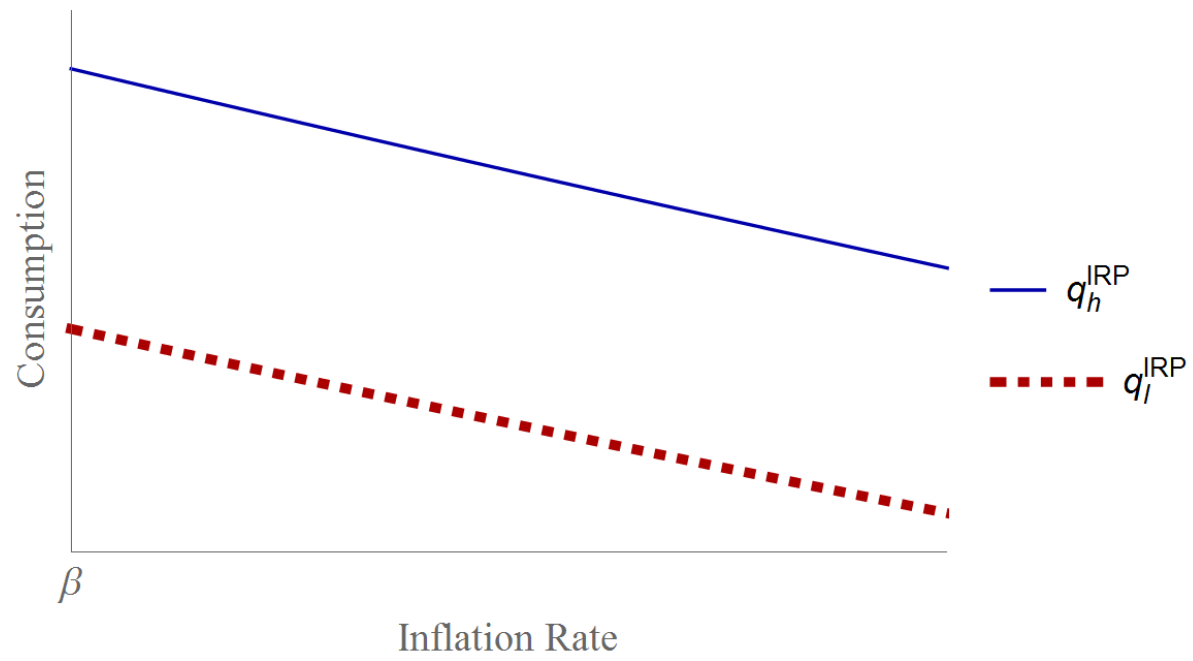

Figure 6: IRP at $\delta=0.5$, consumption over inflation

Proposition 2 Given no information and an IRP, for any set of exogenous variables, there exists a singular, unique steady state equilibrium.

In Figure 7 , the interest rate strictly follows $i_{3}$. The corresponding consumption is depicted in Figure 6 . With high productivity $\varepsilon_{h}$, consumption is strictly higher than with low productivity $\varepsilon_{l}$.

In the Appendix a proof is provided, showing that under an exemplary utility function, the IRP strictly dominates the MSP in terms of welfare. The reasoning for this is found in the equilibrium of 5.1.

The optimal policy with perfect information is pro-cyclical: With high demand, high consumption is preferable and vice versa. A passive MSP does not behave pro-cyclical, whereas a passive IRP does: The money stock policy directly influences consumption. Given a fixed money stock, agents will always spend all available money, unless there spending is unconstrained, in which case they buy $q_{l}^{*}$; in both cases the agents invidivual information of their realised demand does not influence the outcome. The IRP in contrast allows for procyclical behaviour. Given a fixed interest rate, agents can use the information they have to borrow more or less, depending on their demand. The IRP allows for the agents to have their information influence the economy, resulting in pro-cyclical behaviour. 


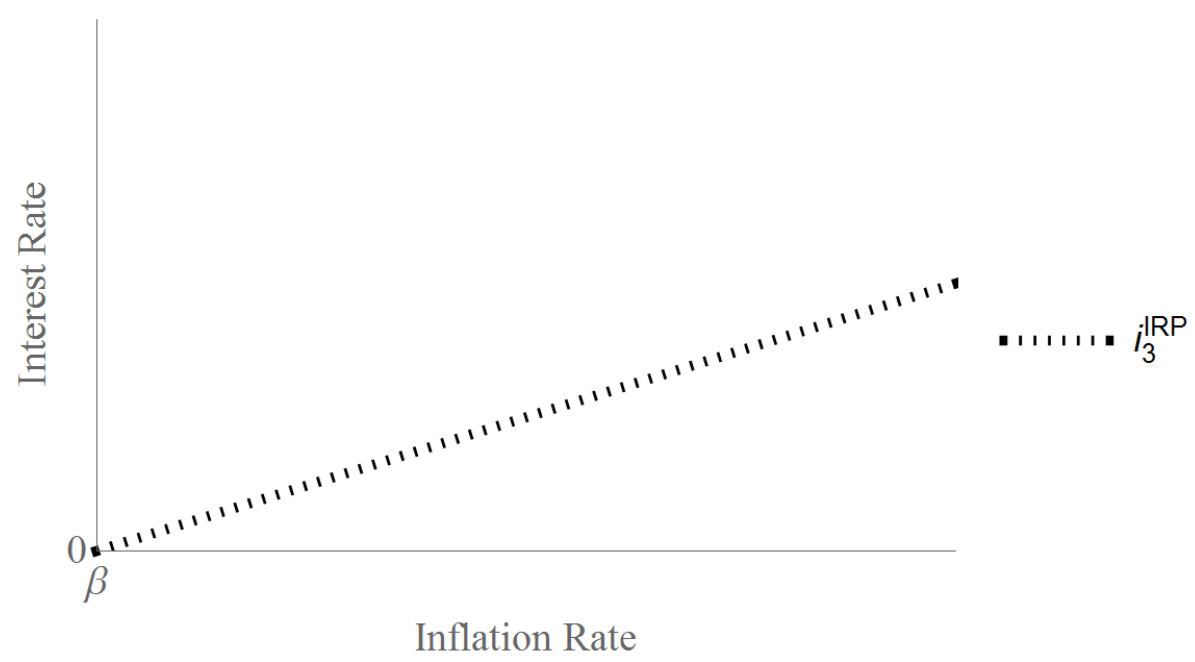

Figure 7: IRP at $\delta=0.5$, interest rate over inflation

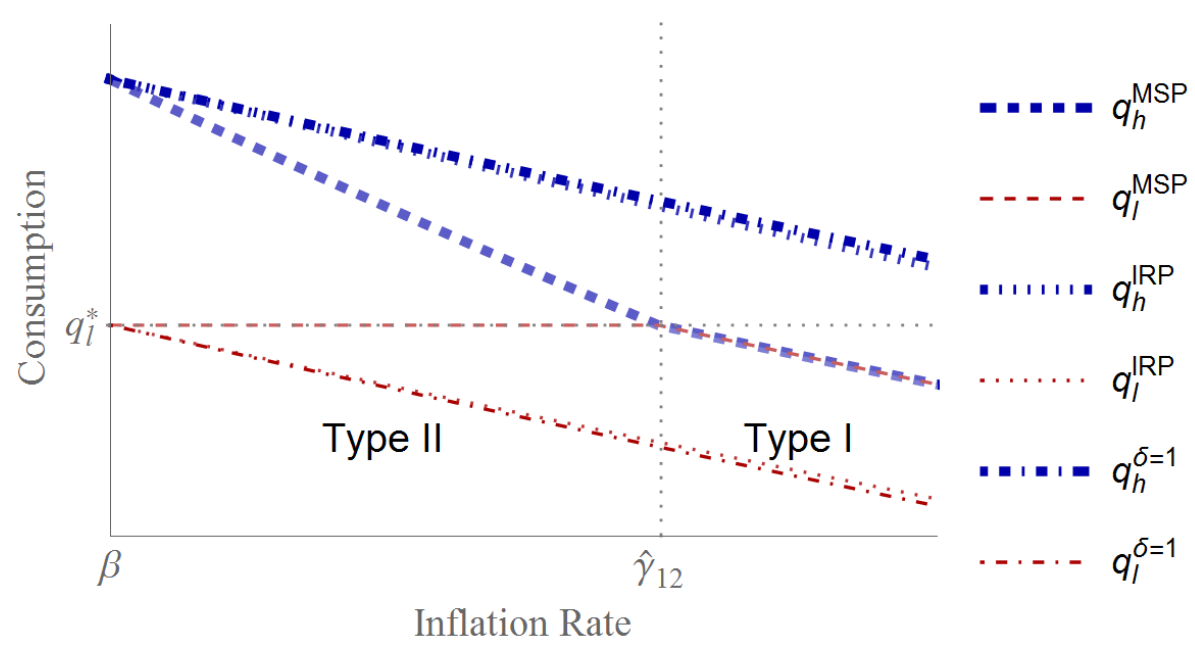

Figure 8: Comparison of equilibria, interest over inflation 


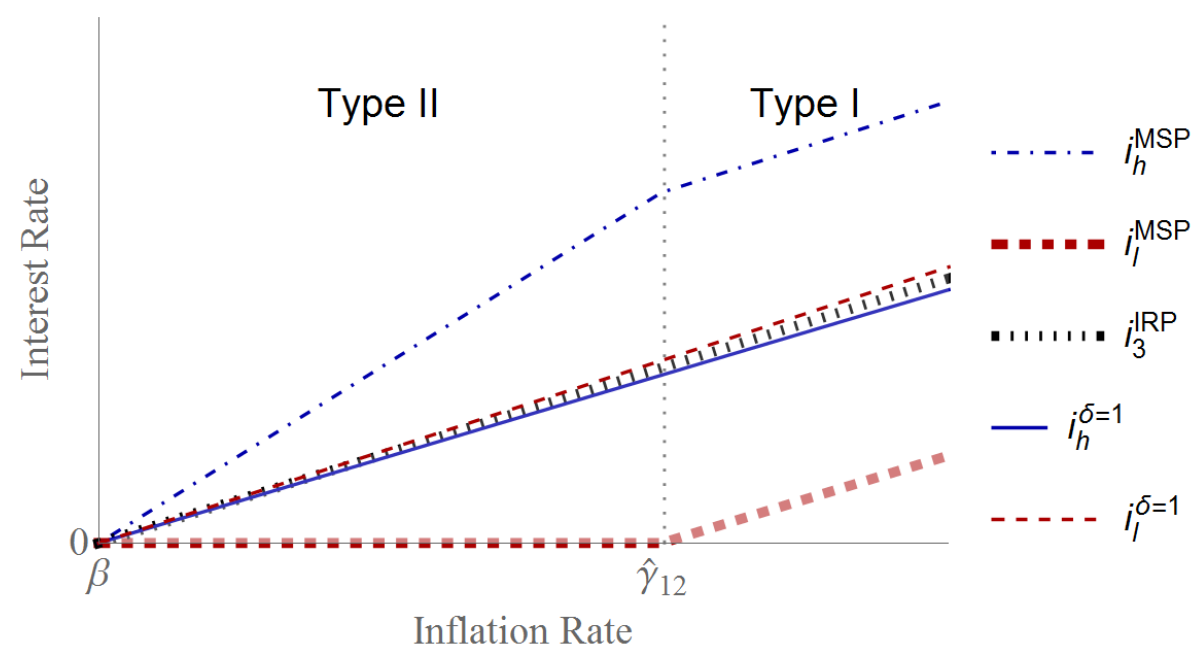

Figure 9: Comparison of equilibria, interest over inflation

Figures (8) and (9) show different consumption and the interest rates of both policies as well as those with perfect information $(\delta=1)$ over different rates of inflation. (A combination of figures (2), 4 and 6 for consumption and 3, 5 and 7 for inflation)

Consumption of the IRP is visually much closer to the consumption of the perfect-information equilibrium than of the MSP. It is slightly lower with high demand, and slightly higher with low demand. The difference seems negligible compared to the difference between the MSP equilibria and perfect information equilibria. To the very left, the Friedman rule is implemented with negative inflation of $\gamma=\beta$. (As money is costless to hold, agents can always carry enough money for efficient consumption, independent of monetary policy). With growing inflation though, the MSP's high demand consumption rapidly drops, as it has to compensate for the growing cost of holding money; it's high demand interest rate is double of the IRP's interest rate in the Type II equilibrium. In the Type I equilibrium, both states interest rates of the MSP grow parallel to $i_{3}$, with the high demand interest rate still being much higher than low demand interest or $i_{3}$.

\subsection{Policy with imperfect information}

Having shed some light on the behaviours of and differences between the MSP and IRP, this chapter will generalize the model and allow for useful, but imper- 
fect information quality with $0.5<\delta<1$. First the MSP will be analyzed, then the IRP.

\subsubsection{Money Stock Policy with imperfect information}

Receiving two signals, the CB can choose two different injections, $T_{l}$ and $T_{h}$. In combination with the two possible utility shocks, four states have to be covered.

Total welfare in the economy can be normalized to

$$
W(1-\beta)=U(x)-x+\sum_{i \in I} \sum_{j \in J} \pi_{i j}\left[n \varepsilon_{i} u\left(q_{i j}\right)-s c\left(\frac{n}{s} q_{i j}\right)\right]
$$

The CB's Ramsey problem is therefore

$$
\begin{gathered}
\max _{q_{h h}, q_{h l}, q_{l h}, q_{l l}} U(x)-x+\sum_{i \in I} \sum_{j \in J} \pi_{i j}\left[n \varepsilon_{i} u\left(q_{i j}\right)-s c\left(\frac{n}{s} q_{i j}\right)\right] \\
\text { s.t. } \\
\frac{\gamma-\beta}{\beta}=\sum_{i \in I} \sum_{j \in J} \pi_{i j}\left[\frac{s}{n} \frac{\varepsilon u^{\prime}\left(q_{i j}\right)}{c^{\prime}\left(\frac{n}{s} q_{i j}\right)}-1\right] \\
q_{l h}=\left\{\begin{array}{c}
q_{h h} \\
q_{l}^{*}
\end{array}\right\} \text { if } q_{h h}\left\{\begin{array}{l}
<q_{l}^{*} \\
\geq q_{l}^{*}
\end{array}\right\} \\
q_{l l}=\left\{\begin{array}{l}
q_{h l} \\
q_{l}^{*}
\end{array}\right\} \text { if } q_{l h}\left\{\begin{array}{l}
<q_{l}^{*} \\
2
\end{array}\right\} \\
q_{h h} \leq q_{h}^{*} \\
q_{h l} \leq q_{h}^{*} .
\end{gathered}
$$

Whereas in subsection 5.2 the CB had one injection for two states, here it has two injections, $T_{h}$ and $T_{l}$ for four states. The possible money holdings may exceed the efficient consumption of that state, hence the terms (17) and (18). The constraints have the same form as the constraint (12) from the analysis of 
MSP without a useful signal.

In contrast to 5.2, more than one equilibrium solution exists, and the $\mathrm{CB}$ is faced with an optimization problem. This creates the necessity of stating the constraints (19) and (20), though they never both bind in an optimized equilibrium. With the injection $T_{h}\left(T_{l}\right)$ being high enough, it is possible for constraint (17) [18] to bind. In this case, buyers would hold enough money to purchase $q_{l}^{*}$ in the state $l h(l l)$. The corresponding Lagrange multipliers of the buyers optimization in the goods market thus can be zero: $\lambda_{l h} \geq 0$ and $\lambda_{l l} \geq 0$.

Depending on the values of $\lambda_{l h}$ and $\lambda_{l l}$, one can identify three types of optimized equilibria for $\gamma>\beta$. Each type of equilibrium will be discussed separately.

Type I equilibrium. In a Type I equilibrium, consumption in all states is inefficient and $\lambda_{i j}>0$ for all $i, j$. In this equilibrium, consumption is such that $q_{h h}=q_{l h}$ and $q_{h l}=q_{l l}$. This reduces the equilibrium condition (9) to

$$
\begin{aligned}
\frac{\gamma-\beta}{\beta} & =\pi_{h} \delta\left[\frac{s}{n} \frac{\varepsilon_{h} u^{\prime}\left(q_{h h}\right)}{c^{\prime}\left(\frac{n}{s} q_{h h}\right)}-1\right]+\pi_{l}(1-\delta)\left[\frac{s}{n} \frac{\varepsilon_{l} u^{\prime}\left(q_{h h}\right)}{c^{\prime}\left(\frac{n}{s} q_{h h}\right)}-1\right] \\
& +\pi_{l} \delta\left[\frac{s}{n} \frac{\varepsilon_{l} u^{\prime}\left(q_{h l}\right)}{c^{\prime}\left(\frac{n}{s} q_{h l}\right)}-1\right]+\pi_{h}(1-\delta)\left[\frac{s}{n} \frac{\varepsilon_{h} u^{\prime}\left(q_{h l}\right)}{c^{\prime}\left(\frac{n}{s} q_{h l}\right)}-1\right]
\end{aligned}
$$

s.t.

$$
\begin{aligned}
& q_{h h}<q_{l}^{*} \\
& q_{h l}<q_{l}^{*}
\end{aligned}
$$

Definition 4 A Type I equilibrium is a path $\left\{q_{h h}, q_{h l}\right\}$ satisfying (21), (23) and (24).

Type II equilibrium. In a Type II equilibrium, consumption is efficient in the state $l h$. In this state, demand for consumption and thus demand for money is low. However, the $\mathrm{CB}$ receives the incorrect signal and increases the available amount of money. The resulting oversaturation of the money market drives the interest rate down to zero, which allows for efficient consumption. In a Type II equilibrium, consumption is such that $q_{l h}=q_{l}^{*}$ and $q_{h l}=q_{l l}$. With $\frac{n}{s} \frac{\varepsilon_{l} u^{\prime}\left(q_{l}^{*}\right)}{c^{\prime}\left(\frac{n}{s} q_{l}^{*}\right)}=1$, the equilibrium condition reduces to 


$$
\begin{aligned}
& \frac{\gamma-\beta}{\beta}=\pi_{h} \delta\left[\frac{n}{s} \frac{\varepsilon_{h} u^{\prime}\left(q_{h h}\right)}{c^{\prime}\left(\frac{n}{s} q_{h h}\right)}-1\right] \\
&+\pi_{l} \delta\left[\frac{n}{s} \frac{\varepsilon_{l} u^{\prime}\left(q_{h l}\right)}{c^{\prime}\left(\frac{n}{s} q_{h l}\right)}-1\right]+\pi_{h}(1-\delta)\left[\frac{n}{s} \frac{\varepsilon_{h} u^{\prime}\left(q_{h l}\right)}{c^{\prime}\left(\frac{n}{s} q_{h l}\right)}-1\right] \\
& q_{h h}<q_{l}^{*} \\
& q_{h l} \geq q_{l}^{*} .
\end{aligned}
$$

Definition 5 A Type II equilibrium is a path $\left\{q_{h h}, q_{h l}\right\}$ satisfying (25), (27) and (28).

Type III equilibrium. Lastly, in a Type III equilibrium, consumption is efficient in both states $l h$ and $l l$. It is not obvious why the CB should optimally implement a policy that oversaturates the money market in states of low demand, independently of the signal.

The intuition is as follows. Imagine an economy with a high spread between $\varepsilon_{h}>>\varepsilon_{l}$ and a high probability of realization of the high consumption preference state $\pi_{h}>>\pi_{l}$. The Bayesian problem the CB faces states that given the signal of a low state, the state $h l$ is more likely than the state $l l$. The optimal trade-off between both possibilities may result in an over saturation in state $l l$, in which case the economy is in a Type III equilibrium. Now $q_{l h}=q_{l l}=q_{l}^{*}$, simplifying the equilibrium condition to

$$
\frac{\gamma-\beta}{\beta}=\pi_{h} \delta\left[\frac{n}{s} \frac{\varepsilon_{h} u^{\prime}\left(q_{h h}\right)}{c^{\prime}\left(\frac{n}{s} q_{h h}\right)}-1\right]+\quad \pi_{h}(1-\delta)\left[\frac{n}{s} \frac{\varepsilon_{h} u^{\prime}\left(q_{h l}\right)}{c^{\prime}\left(\frac{n}{s} q_{h l}\right)}-1\right]
$$

s.t.

$$
\begin{aligned}
& q_{h h} \geq q_{l}^{*} \\
& q_{h l} \geq q_{l}^{*} .
\end{aligned}
$$

Definition 6 A Type III equilibrium is a path $\left\{q_{h h}, q_{h l}\right\}$ satisfying (29), (30) and (31).

The following table summarizes the Lagrange multipliers and quantities consumed in the different types of equilibria. 
Type I Type II Type III

\begin{tabular}{|c|c|c|c|}
\hline$\lambda_{h h}$ & $>0$ & $>0$ & $>0$ \\
\hline$\lambda_{h l}$ & $>0$ & $>0$ & $>0$ \\
\hline$\lambda_{l h}$ & $>0$ & $=0$ & $=0$ \\
\hline$\lambda_{l l}$ & $>0$ & $>0$ & $=0$ \\
\hline$q_{l h}$ & $=q_{h h}$ & $=q_{l}^{*}$ & $=q_{l}^{*}$ \\
\hline$q_{l}$ & $=q_{h l}$ & $=q_{h l}$ & $=q_{l}^{*}$ \\
\hline
\end{tabular}

Proposition 3 For any set of exogenous variables, given a MSP, there exists a unique steady state welfare-maximizing equilibrium of either Type I, Type II or Type III.

The type of equilibrium found in an optimized economy depends on the exogenous variables. ${ }^{1}$ Due to the complexity of the problem, only the qualitative description of the influences of the variables on the optimized equilibria is discussed here. ${ }^{2}$ When changing a single exogenous variable, the resulting equilibrium may change between Type I and Type II, and between Type II and Type III. No 'Jump' from Type I to Type III or vice versa can happen without passing through Type II territory. Given this linearity, Type III equilibria are considered more 'extreme' than those of Types I and II, which eases the following discussion. The exogenous variables are the $\varepsilon$, the 'high demand state' probability $\pi$, the quality of information $\delta$, the discount rate $\beta$, and lastly the inflation rate $\gamma$, given the short-term horizon. The corresponding figures are in the Appendix, so as not to clutter the text. The following observations can be made:

With a bigger difference between $\varepsilon_{h}$ and $\varepsilon_{l}$, that is with $\varepsilon_{h}>>\varepsilon_{l}$, equilibria tend to be more extreme: they shift in the direction of a Type III equilibrium.

\footnotetext{
${ }^{1}$ For clarity I have omitted the technically possible Type IV equilibrium. If the injection $T_{l}$ chosen to be higher than the injection $T_{h}$, an equilibrium would be possible in which $q_{l l}=q_{l}^{*}$, $q_{l h}=q_{h h}$ and equivalently $\lambda_{l l}=0$ and $\lambda_{l h}>0$. This equilibrium is viable, though never optimal.

${ }^{2}$ This should not be of much concern however, as the existence of separate types of equilibria is due only to the choice of discrete states of $\varepsilon$, instead of a statistical distribution.
} 


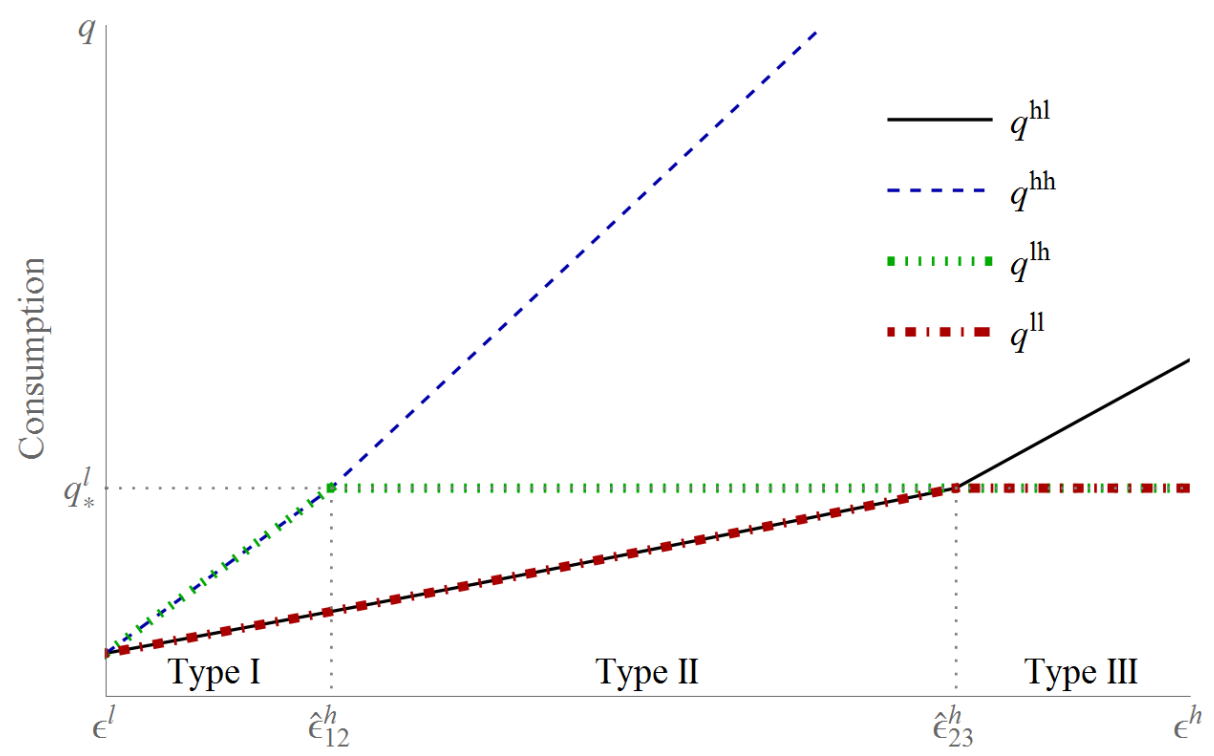

Size of High Preference Shock

Figure 10: MSP, consumption over high demand factor

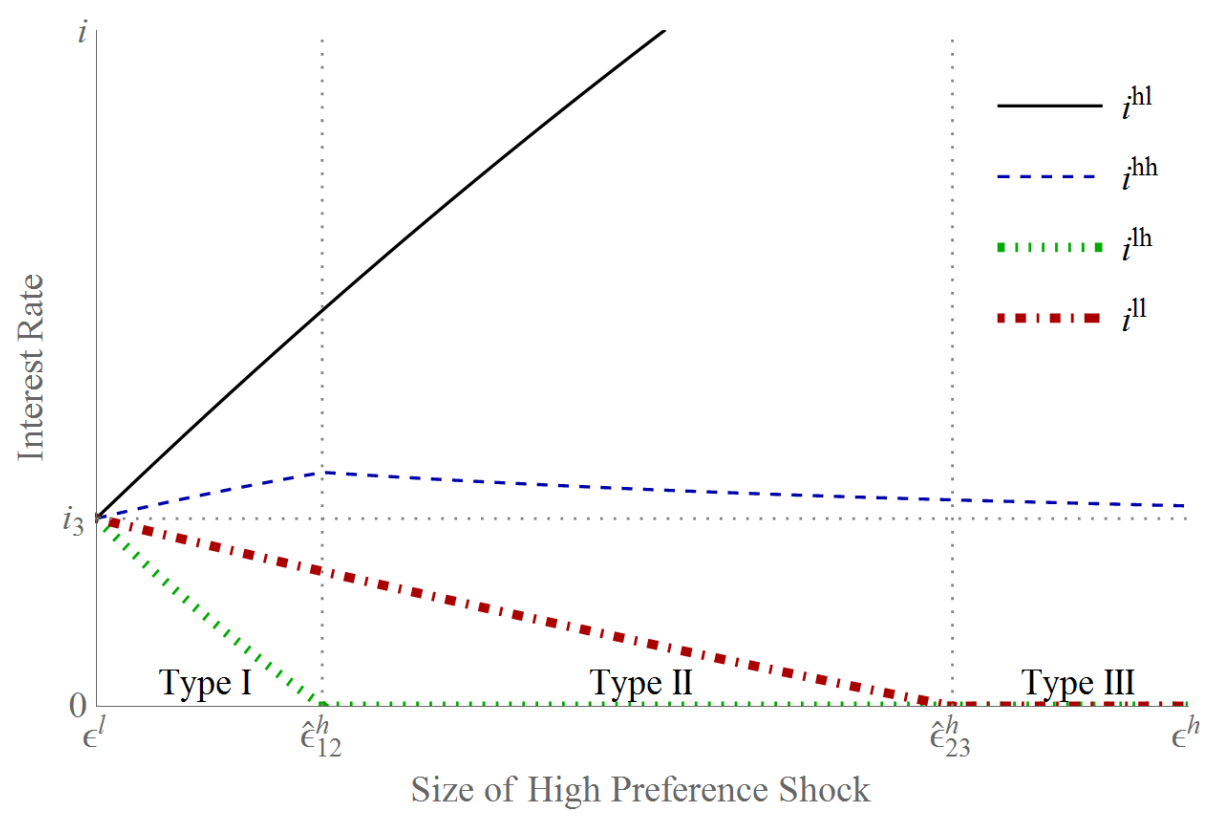

Figure 11: MSP, interest rates over high demand factor 


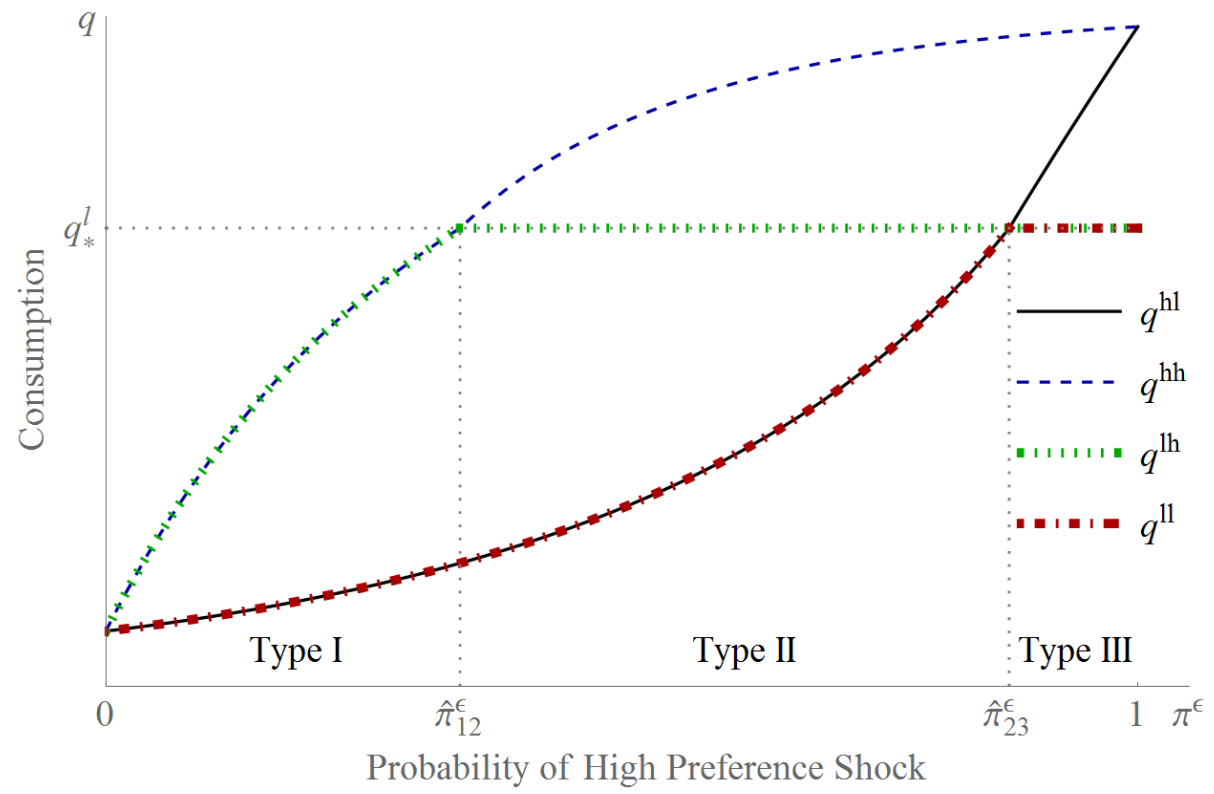

Figure 12: MSP, consumption over probability of high demand

Figures (10) and (11) show the consumption and interest rates of equilibria with varying $\varepsilon_{h}$, keeping all other exogenous variables fixed. The optimal policy focusses on utilizing the states with $\varepsilon_{h}$, which easily leads to oversaturation in states with $\varepsilon_{l}$.

A higher probability of a high preference state $\pi$ results in more extreme equilibria. This is reasonable: the $\mathrm{CB}$ shifts its policy to the utilization of the high state. See Figures (12) and (13).

A higher information quality $\delta$ results in more extreme equilibria. With fewer fail cases, the CB's policy does not have to be as conservative, and a bigger spread between $q_{l}$ and $q_{h}$ is optimal. See Figures (14) and (15).

Either a lower inflation rate or a lower discount rate shift the equilibria more to the extreme. As the cost of holding money decreases, it is more beneficial to have money for the high demand state than it is costly to bring too much to a low demand state. See Figures (16) and (17).

A minor note can be made about the different types of equilibria found with the MSP. The differentiation into types is a property emerging from the two state nature of this model. If one were to write the model with shocks with a continuous distribution, there would always be a probability of landing in a 


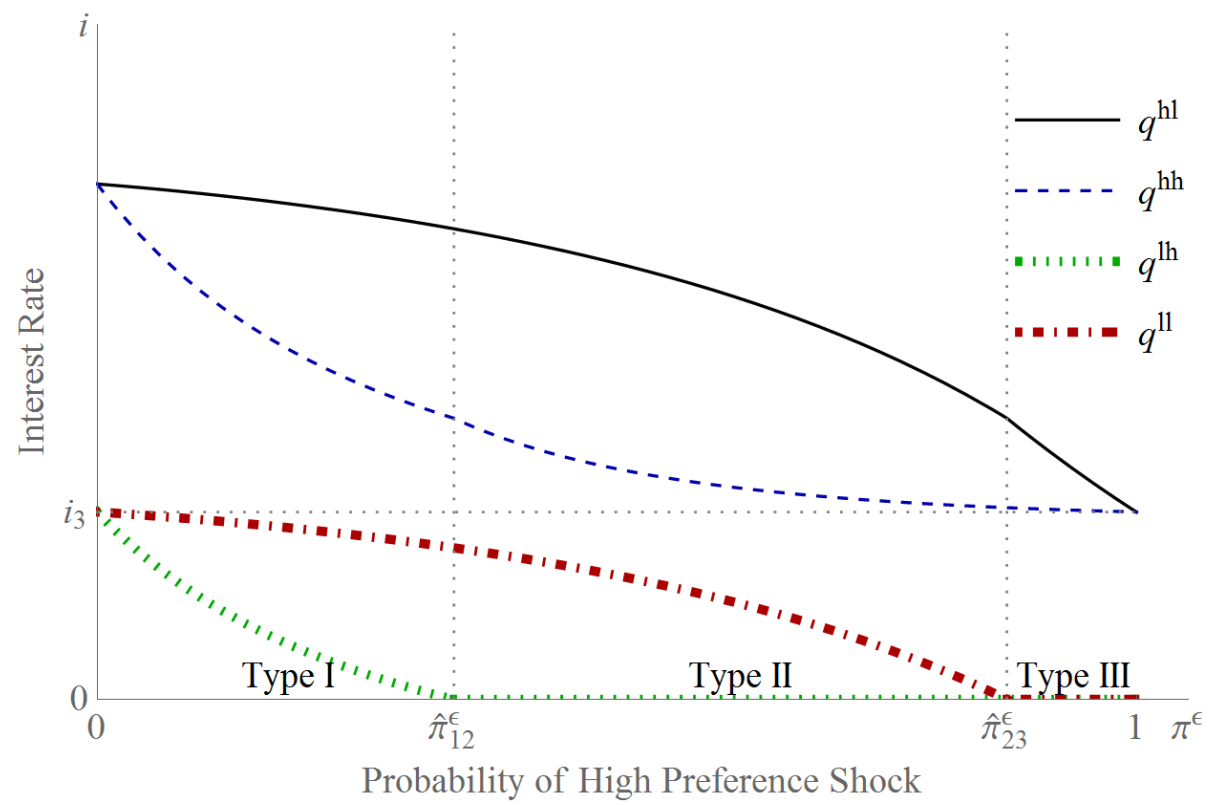

Figure 13: MSP, interest rates over probability of high demand

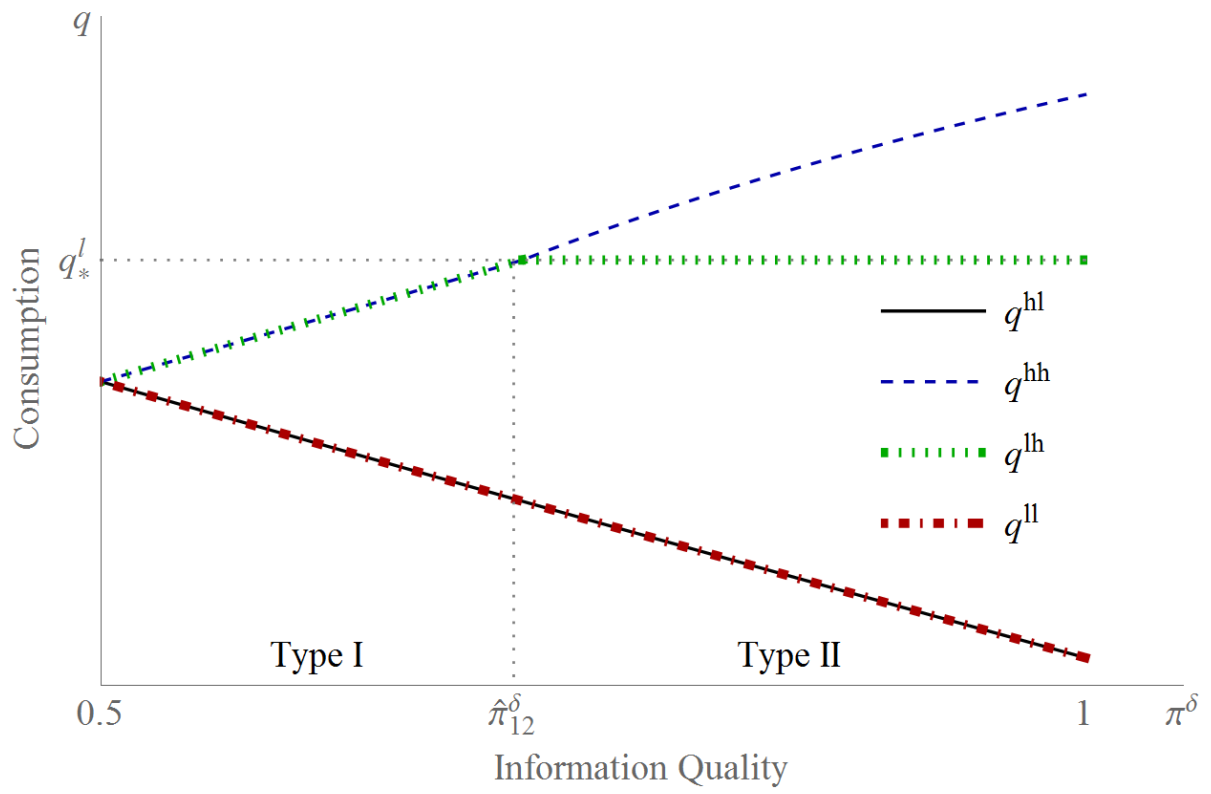

Figure 14: MSP, consumption over information quality 


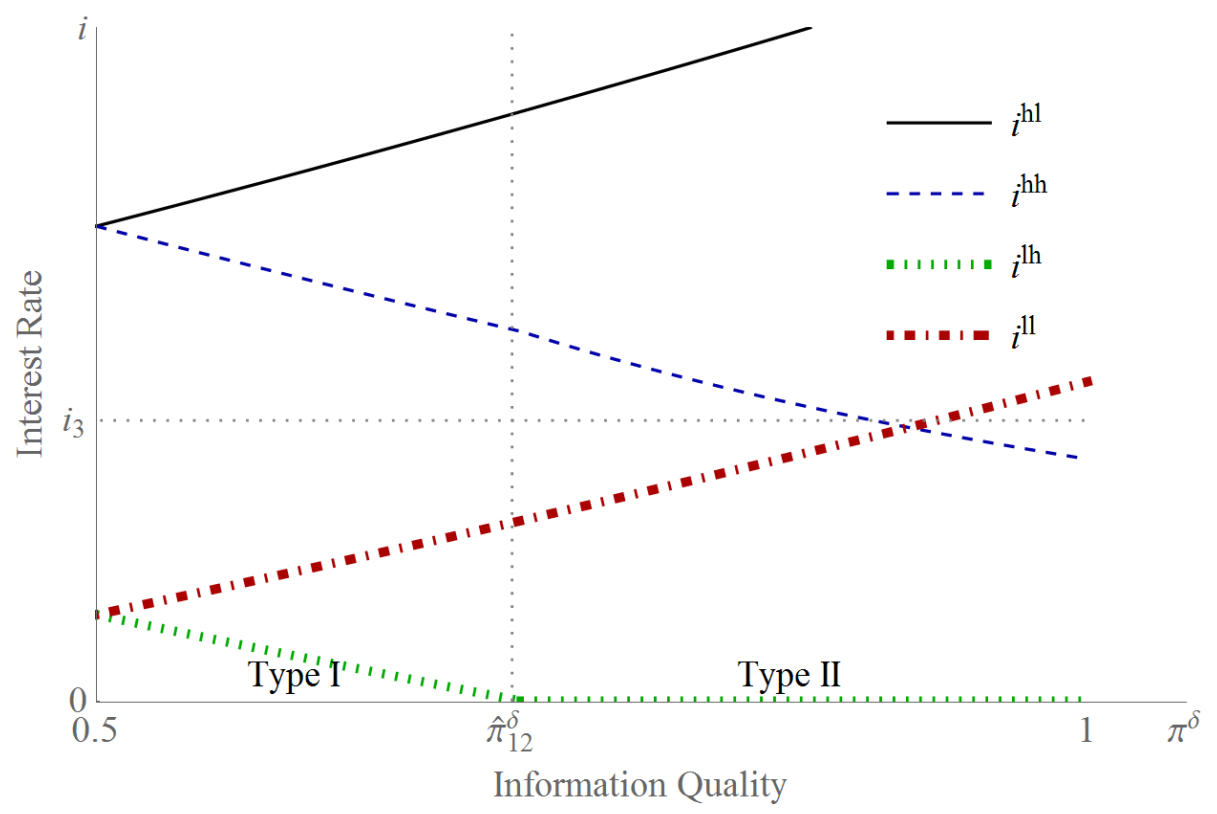

Figure 15: MSP, interest rates over information quality

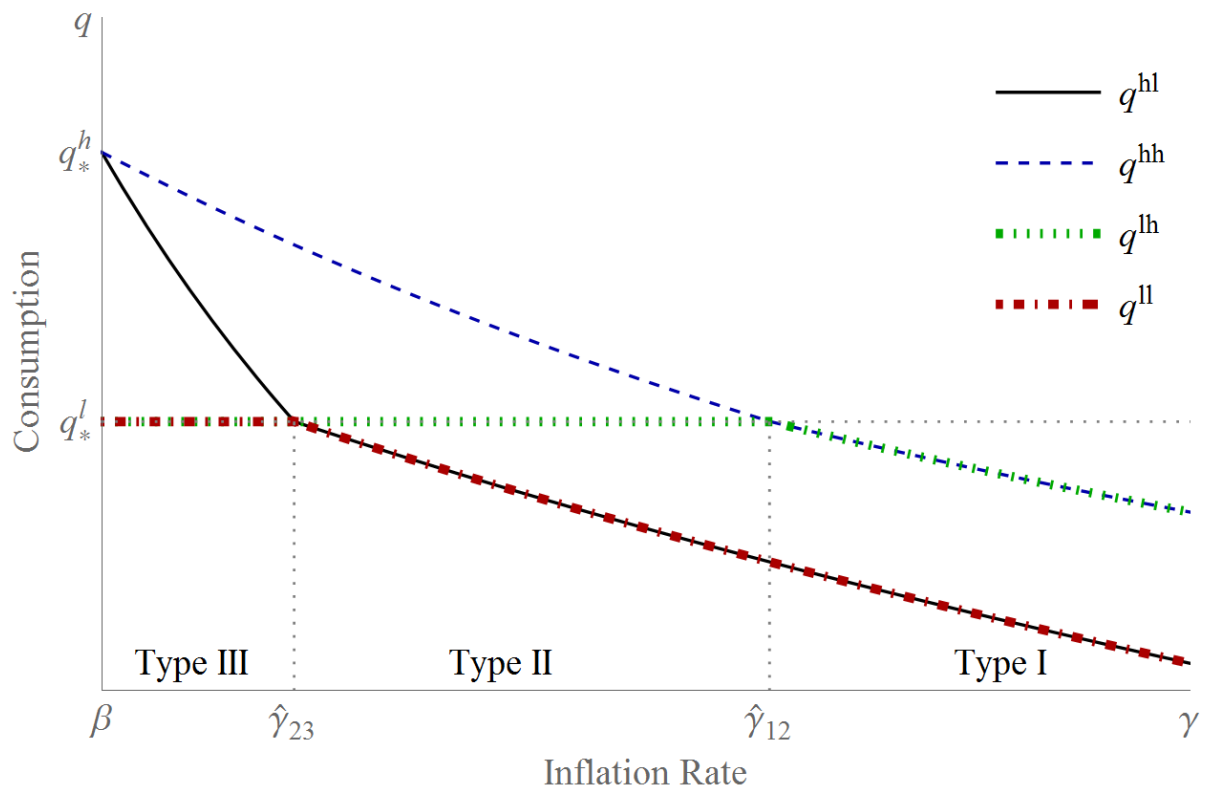

Figure 16: MSP, consumption over inflation 


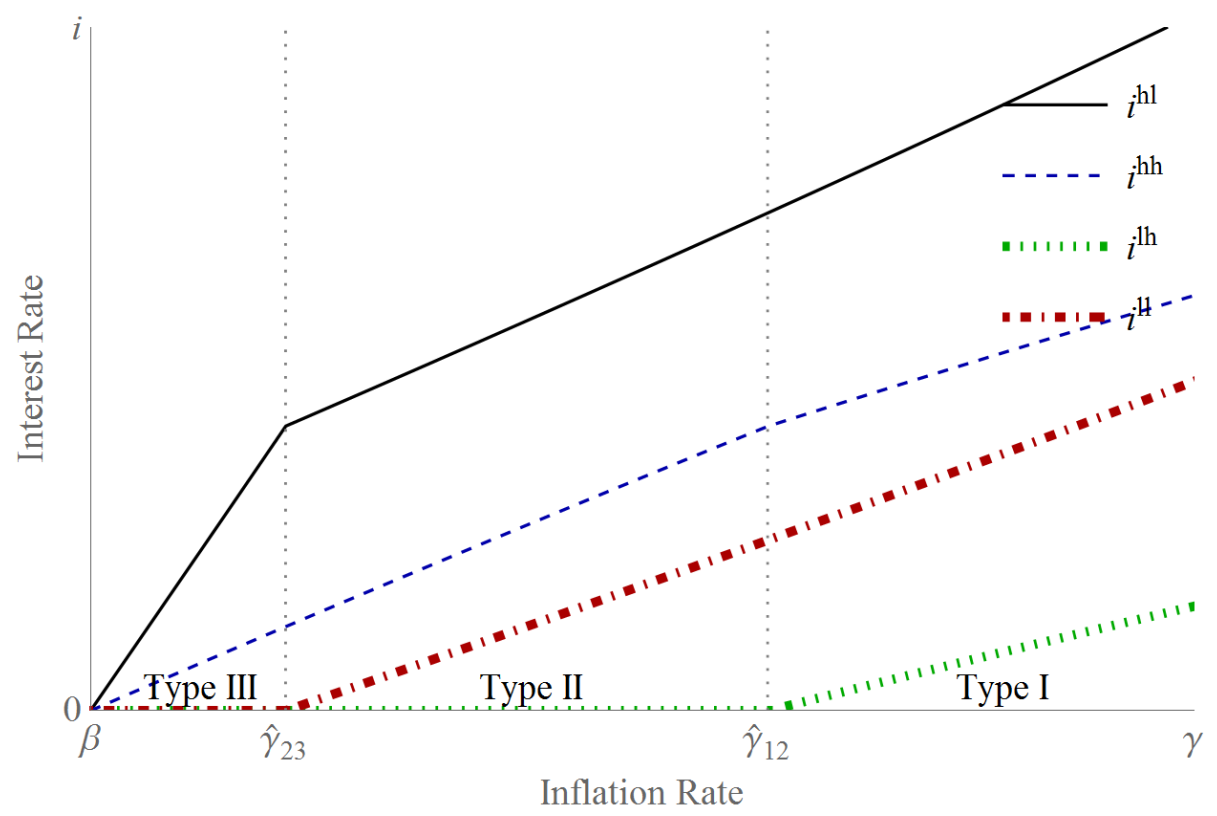

Figure 17: MSP, interest rates over inflation

state meeting the zero lower bound of interest. This would occur in those cases, where the $\mathrm{CB}$ expects relatively high demand but finds relatively low demand.

\subsubsection{Interest Rate Policy with imperfect information}

In a IRP, only two interest rates exist in the four different states. Given the signal $j$, the CB sets the interest rate of the standing facility to $i_{j}$, so that $i_{j}$ is the interest rate in both states $h j$ and $l j$. Knowing this and (13), the quantities $q_{i j}$ can be related with the following statements.

$$
\begin{aligned}
& \varepsilon_{l} \frac{u^{\prime}\left(q_{l l}\right)}{c^{\prime}\left(\frac{n}{s} q_{l l}\right)}=\varepsilon_{h} \frac{u^{\prime}\left(q_{h l}\right)}{c^{\prime}\left(\frac{n}{s} q_{h l}\right)} \\
& \varepsilon_{l} \frac{u^{\prime}\left(q_{l h}\right)}{c^{\prime}\left(\frac{n}{s} q_{l h}\right)}=\varepsilon_{h} \frac{u^{\prime}\left(q_{h h}\right)}{c^{\prime}\left(\frac{n}{s} q_{h h}\right)}
\end{aligned}
$$

Thus, the CB's Ramsey problem is as follows. 


$$
\begin{gathered}
\max _{q_{h h}, q_{h l}, q_{l h}, q_{l l}} U(x)-x+\sum_{i \in I} \sum_{j \in J} \pi_{i j}\left[n \varepsilon_{i} u\left(q_{i j}\right)-s c\left(\frac{n}{s} q_{i j}\right)\right] \\
\text { subject to } \\
\frac{\gamma-\beta}{\beta}=\pi_{h} \delta\left[\varepsilon_{h} \frac{n}{s} \frac{u^{\prime}\left(q_{h h}\right)}{c^{\prime}\left(\frac{n}{s} q_{h h}\right)}-1\right]+\left(1-\pi_{h}\right)(1-\delta)\left[\varepsilon_{l} \frac{n}{s} \frac{u^{\prime}\left(q_{l h}\right)}{c^{\prime}\left(\frac{n}{s} q_{l h}\right)}-1\right] \\
+\pi_{h}(1-\delta)\left[\varepsilon_{h} \frac{n}{s} \frac{u^{\prime}\left(q_{h l}\right)}{c^{\prime}\left(\frac{n}{s} q_{h l}\right)}-1\right]+\left(1-\pi_{h}\right) \delta\left[\varepsilon_{l} \frac{n}{s} \frac{u^{\prime}\left(q_{l l}\right)}{c^{\prime}\left(\frac{n}{s} q_{l l}\right)}-1\right] \\
\varepsilon_{l} \frac{u^{\prime}\left(q_{l h}\right)}{c^{\prime}\left(\frac{n}{s} q_{l h}\right)}==\varepsilon_{h} \frac{u^{\prime}\left(q_{h h}\right)}{c^{\prime}\left(\frac{n}{s} q_{h h}\right)} \\
\varepsilon_{l} \frac{u^{\prime}\left(q_{l l}\right)}{c^{\prime}\left(\frac{n}{s} q_{l l}\right)}==\varepsilon_{h} \frac{u^{\prime}\left(q_{h l}\right)}{c^{\prime}\left(\frac{n}{s} q_{h l}\right)}
\end{gathered}
$$

Definition 7 A steady state IRP equilibrium is any path $\{q h h, q h l\}$ that solves (34) and (37).

Proposition 4 For any set of exogenous variables, given imperfect information and a IRP, there exists a unique steady state welfare-maximizing equilibrium.

Figure (19) depicts the interest rates of equilibria with different information qualities under a IRP, all other exogenous variables being equal. Although $i_{l}=i_{h}=i_{3}$ at $\delta=0.5$, with growing information quality, the CB chooses interest rates with growing differences, closer to the optimal target. The according amounts of consumption are shown in Figure (18). In this example, both consumptions in the states with high productivity $h h$ and $h l$ are above the efficient consumption of the low productivity states $q_{l}^{*}$. With growing information quality, $q_{h h}$ becomes closer to $q_{h}^{s}$, whereas $q_{h l}$ becomes further away from it. The equivalent can be found in the low productivity states. As the signal becomes more informative, the states $h h$ and $l l$ become more likely, and the CB can put a bigger weight on optimizing them at the trade-off of optimizing $l h$ and $h l$. 


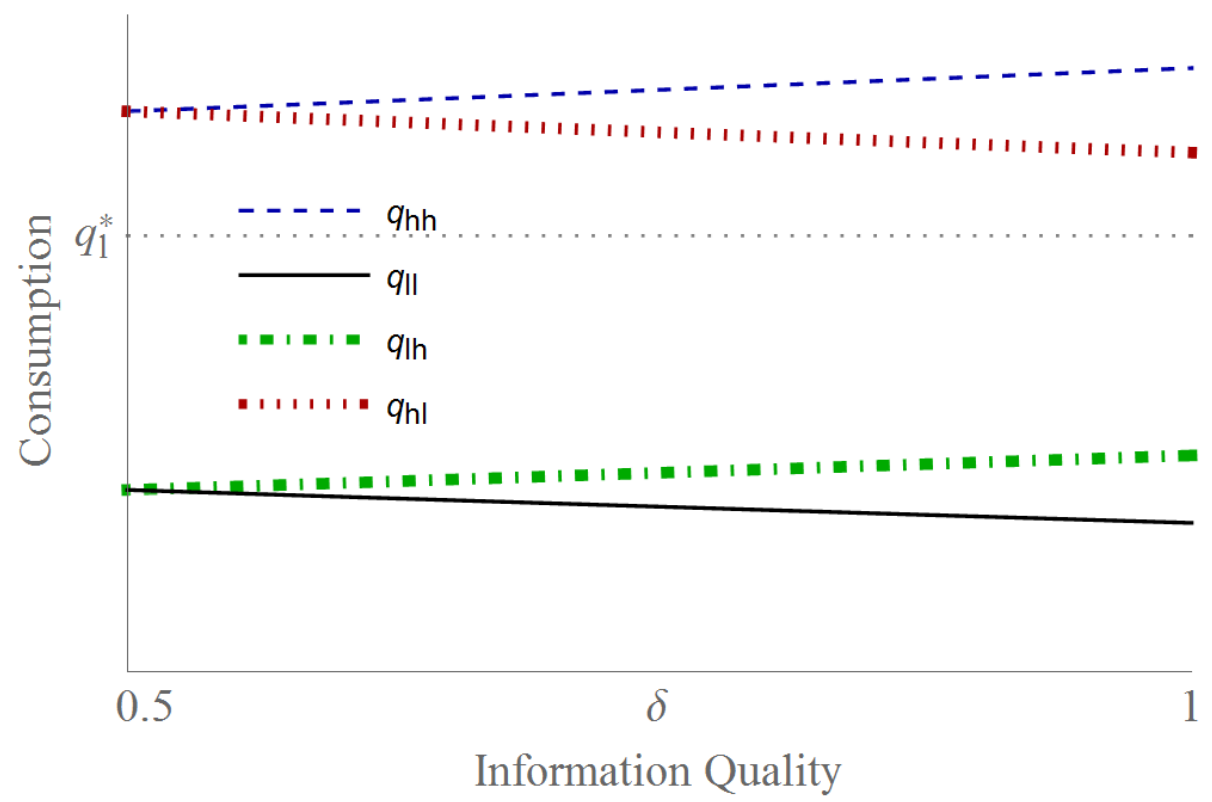

Figure 18: Consumption under interest rate policy

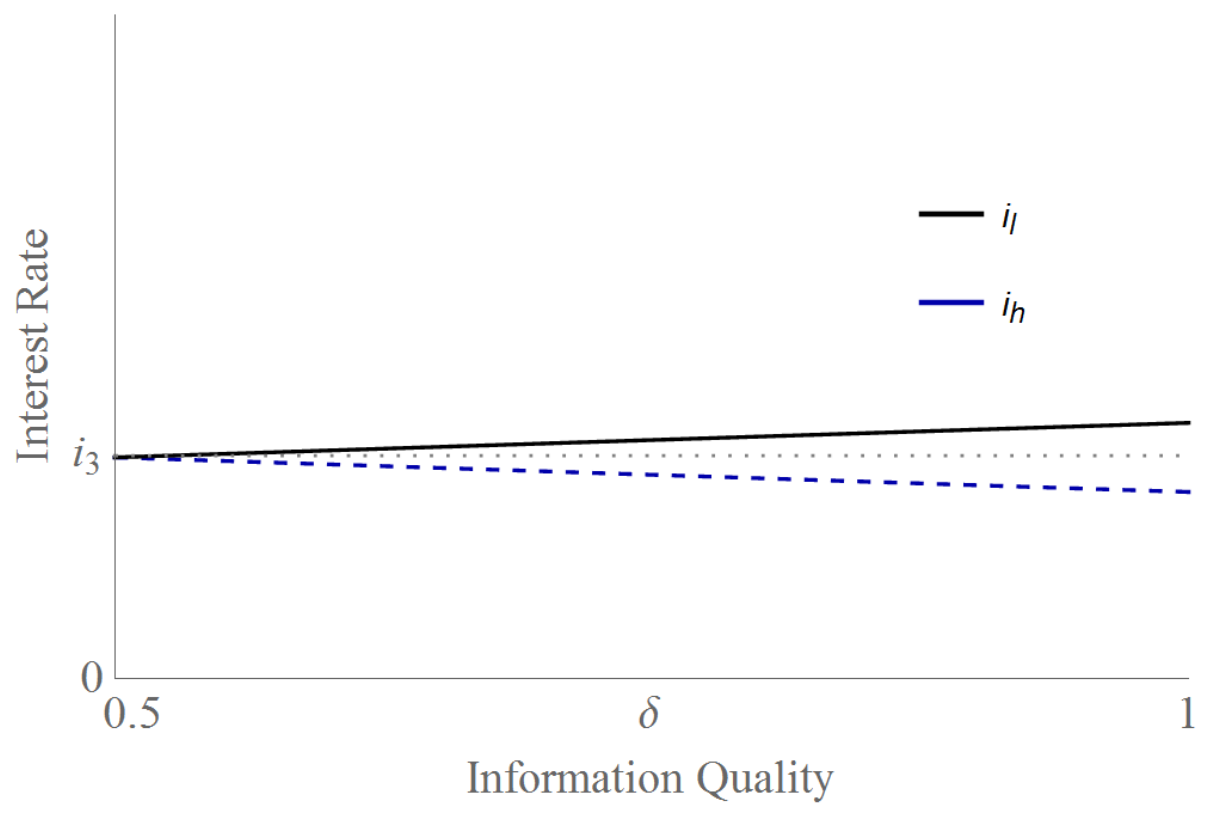

Figure 19: Interest rates under interest rate policy 


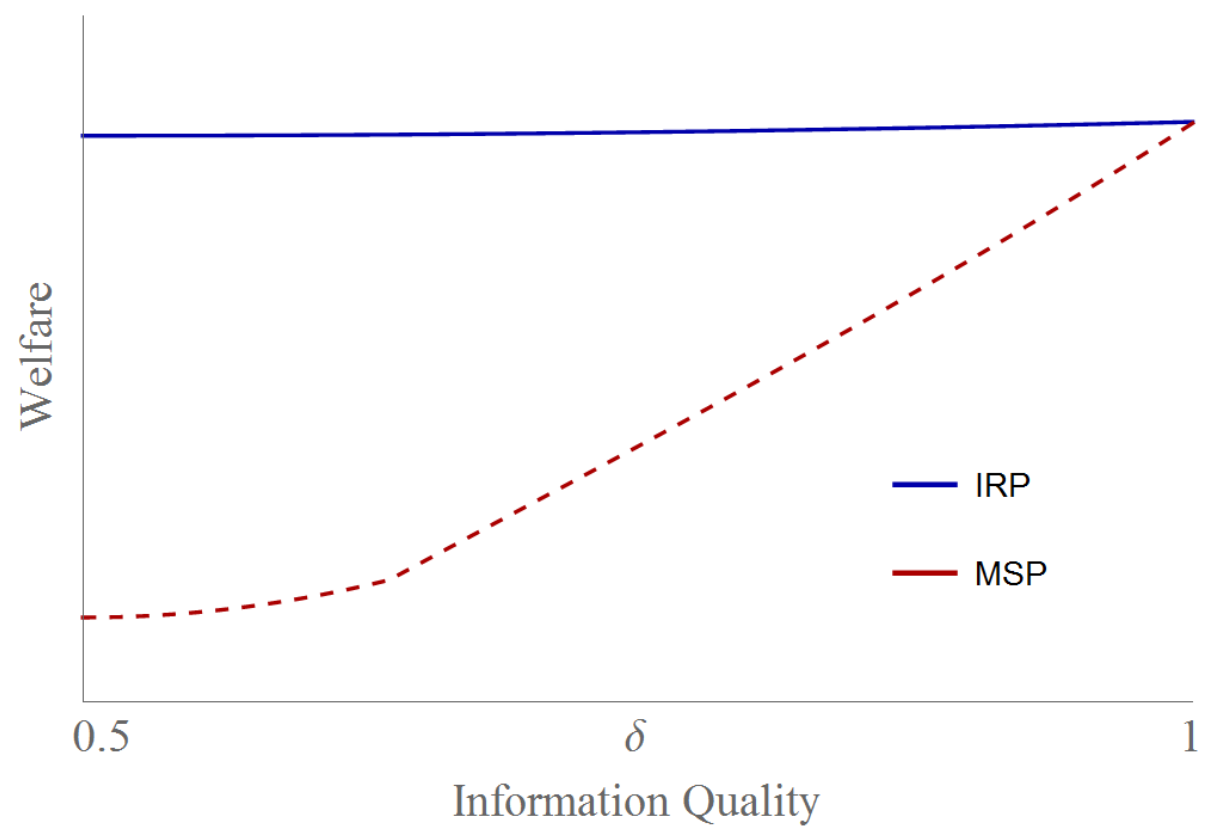

Figure 20: Welfare of both policies over information quality

Figure (20) has been calculated numerically. It depicts the welfare for equilibria under each policy for different qualities of information. All other exogenous variables are selected exemplatory and fixed for both policies and all points. The $\mathrm{CB}$ is behaving so as to maximize welfare given each policy. In all tested cases with imperfect information, the IRP creates higher welfare than the MSP. No set of variables has been found, where in the MSP creates higher welfare than the IRP. The only special case of course is with $\delta=1$, as both policies carry the same result.

\section{Discussion}

This model's answer to the target problem is the optimality of an interest ratebased policy for short-term optimization. However, this result has to be regarded in a greater context, as it stands in contrast to other research in this area. This conflict reveals itself in the axioms of the different theoretical approaches to the problem.

To clarify this, compare this model with one of the first major papers on the target problem, [Poole, 1970]. Poole takes a macro approach using an IS- 


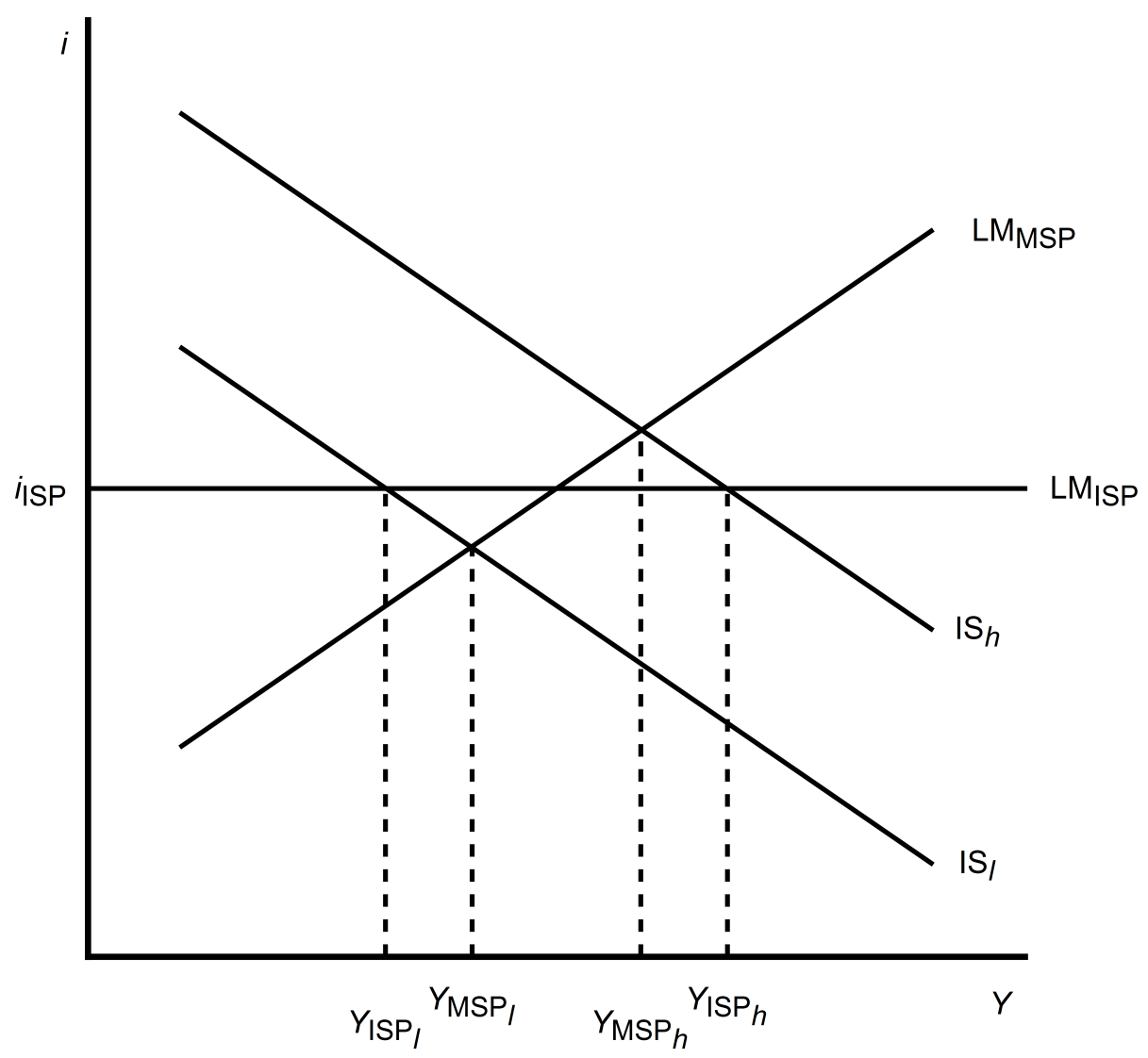

Figure 21: Shock to the $I S$ curve in [Poole, 1970]

LM model to research the question as to whether a steady interest rate or a steady money supply is the better tool for an economy with aggregate shocks. To summarize [Poole, 1970], the model investigates shocks to the goods market as well as shocks to the money market.

Given a shock to the goods market, Poole finds a fixed money stock to produce better stabilization of the economy and to be the preferred tool. In Figure (21), I $S_{h}$ and $I S_{l}$ present two examples of states in the goods market. The curve $L M_{M S P}$ shows the money demand curve under a MSP, and $L M_{I R P}$ shows that under a IRP. From the cross sections, the income levels $Y_{I R P_{l}}, Y_{M S P_{l}}$, $Y_{M S P_{h}}$ and $Y_{I R P_{h}}$ follow. As the income levels with a fixed interest rate are spread wider than with a fixed money stock, [Poole, 1970] concludes that the MSP is the optimal choice given only a shock to the goods market. 


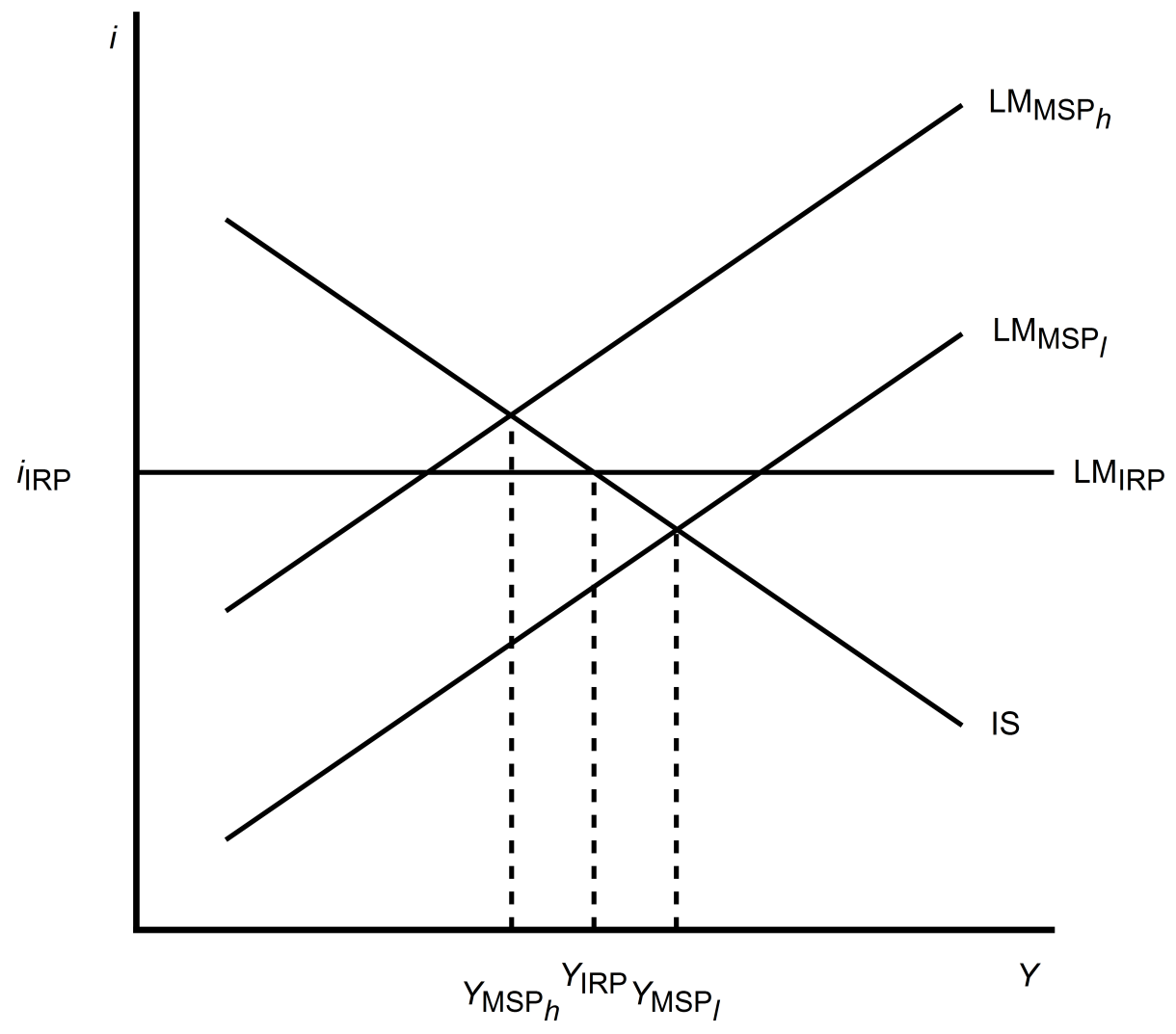

Figure 22: Shock to the $L M$ curve in [Poole, 1970] 
Given a shock to the money demand curve, Poole finds the opposite to be the case. The money demand shock is represented by the two curves, $L M_{M S P_{h}}$ and $L M_{M S P_{l}}$ in Figure (22). From the cross sections with the $I S$ curve, two levels of income $Y_{M P S_{h}}$ and $Y_{M S P_{l}}$ follow. With a fixed interest rate, however, the shock in money demand has no influence on the income level $Y_{I R P}$. As the variance in income levels is higher under a MSP than under a IRP, Poole concludes that given a shock to money demand, the IRP is the optimal choice.

To compare this paper's model with [Poole, 1970], some equivalences have to be captured. First, the income $Y$ of the model of [Poole, 1970] corresponds to the consumption $q$ in a model with a Lagos-Wright framework. Second, the aggregate consumption shock $\varepsilon$ is equivalent to a shift of the $I S$ curve. Third, as Poole looks at passive policies, for a comparison the IRP is best modelled as a standing facility with minimal information quality $\delta=0.5$, so that one interest rate is set for all states. This is directly equivalent to [Poole, 1970]'s standing facility. Lastly, with respect to the MSP, for simplicity and clarity, only Type I equilibria are examined, where the zero lower bound is not met in any state. In a Type I equilibrium and under $\delta=0.5$, the MSP fixes consumption of $q$ independent of the state. This is equivalent to a completely inelastic $L M$ curve, as shown in Figure (23). 


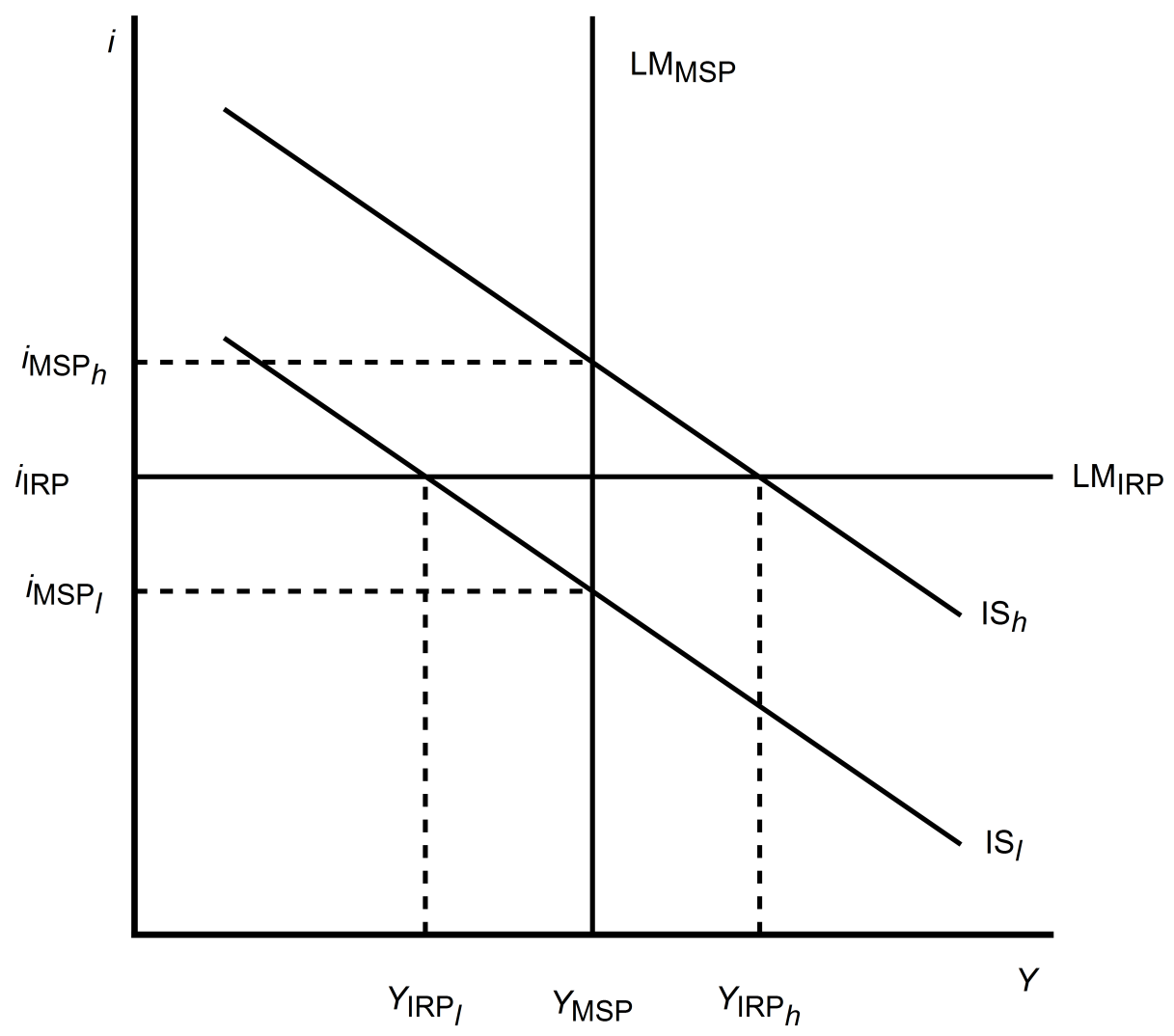

Figure 23: Comparison of MSP and IRP

Interestingly, with comparable shocks, both models give qualitatively equal results in terms of the income levels. A standing facility with interest rate $i_{I R P}$ leads to two levels of consumption $Y_{I R P_{l}}$ and $Y_{I R P_{h}}$, whereas a fixed money stock results in one level of consumption $Y_{M S P}$ and two interest rates $i_{M S P_{l}}$ and $i_{M S P_{h}}$. This is the case in the IS-LM model as well as in this paper's model.

The important difference now lies in the interpretation of the variance of the income levels (which translates to consumption levels in this model). [Poole, 1970]'s benchmark for comparing the effectiveness of the policies is the reduction of variance of consumption. Most New Keynesian models use the minimization of a quadratic loss function as their benchmark for policies (see [Cecchetti, 2000]). Most New Monetarist models, along with the model developed here, use an aggregate utility function, defining higher expected utility as better. This 
paper's model finds the IRP dominating, when comparing for welfare; whereas, if stabilization of output is the measure, the MSP dominates, as it does in [Poole, 1970].

Given this important axiomatical difference of the two approaches, it follows that there should be a distinction in terminology. This paper's proposal is to use the term stabilizing policy with regards to policies that use something akin to the minimization of a quadratic loss function to reduce volatility of one (or more) variables, such as, inflation, interest rates or output. In contrast, a policy that maximizes welfare should be called welfare-maximizing policy. Both policies would be coined optimizing policies, as their performance is optimized in regards to their defined target.

There are good arguments for both policy approaches. A major argument for a welfare-maximizing policy is, that, in the end, no agent cares about interest rates per se, but about actual food on their table. Policies are designed for the benefit of human agents, thus their utility is the most important variable. A major argument for stabilizing targets is their actual implementability and measurability. While in reality we cannot measure the abstract "utility" of agents, interest rates, output and inflation are, of course, readily measured. Taking the best of both approaches, an evolution of the research question could be akin to: What practically implementable tool and measurable target leads, in theoretical models, to the highest aggregate utility of agents?

Some recent New Keynesian papers have had the ambition to implement a solid microfoundation and taking in to consideration agents' utility, which given the aforementioned thoughts seems commendable. [Woodford, 2010] actually implements both approaches in his model, and can compare stabilization with a quadratic loss function to maximization of utility. He does so in a microfounded New Keynesian model, wherein households maximize their utility. Interestingly, his finding is an equivalence of utility maximization and stabilization policy. While this cannot be the general case, as this models comparison to [Poole, 1970] reveals, the translation of Woodfords model with sticky prices to a New Monetarist model would be interesting in future research.

This discussion highlights the importance of the foundational axioms for economic models and studies. As all results and insights are derived from axioms, one has to be aware of them and be able to challenge and further develop them. 


\section{Conclusion}

This paper gives a microfounded answer to the target problem. By adding imperfect information to the model of [Berentsen and Waller, 2011], a divide between a policy based on interest rate manipulation and a policy based on short-term injections of money emerges. With this, the usefulness of both policies is analyzed, with the result being the dominance of an pro-cyclical interest rate based policy. This finding stands in contrast to the interpretation of the model of [Poole, 1970], in both the optimality of a pro-cyclical policy as well as the optimality of an interest rate target. In future research, several different

shocks, including government spending, may be added, to research whether an interest rate based policy still dominates. 


\section{Appendix}

Proof that IRP strictly dominates MSP with delta $=0.5$ and an exemplary utility function and with extrinsic variables such that the equilibrium is of Type I under an MSP.

The exemplary utility function is

$$
\begin{gathered}
u(q)=2 q^{0.5} \\
c(q)=q .
\end{gathered}
$$

Assume the extrinsic variables satisfy

$$
q_{M S P}<q_{l}^{*}
$$

which, given the above assumptions, can be rewritten as

$$
\frac{\beta}{\gamma} \frac{s}{n}\left(\varepsilon_{l} \pi_{l}+\varepsilon_{h} \pi_{h}\right)<\varepsilon_{l}
$$

so that the MSP equilibrium is of Type I.

To prove the strict dominance of the IRP, compare the utilities of both policies.

The expected welfare of a representative period is

$$
\begin{gathered}
U=p_{h}\left[n \varepsilon_{h} u\left(q_{h}\right)-s c\left(\frac{n}{s} q_{h}\right)\right]+p_{l}\left[n \varepsilon_{l} u\left(q_{l}\right)-s c\left(\frac{n}{s} q_{l}\right)\right] \\
U=p_{h}\left[n \varepsilon_{h} \frac{q_{h}^{1-a}}{1-a}-n q_{h}\right]+p_{l}\left[n \varepsilon_{l} \frac{q_{l}^{1-a}}{1-a}-n q_{l}\right] .
\end{gathered}
$$

To calculate the utility of the economy under an MSP, solve for $q$ : 


$$
\begin{gathered}
\frac{\beta}{\gamma} \frac{s}{n}=\pi_{l} \varepsilon_{l} q l^{-} a+\pi_{h} \varepsilon_{h} q h^{-} a \\
q_{l}^{M S P}=q_{h}^{M S P}=q^{M S P} \\
q^{M S P}=\left[\frac{\beta}{\gamma} \frac{s}{n}\left(\pi_{l} \varepsilon_{l}+\pi_{h} \varepsilon_{h}\right)\right]^{(1 / a)} .
\end{gathered}
$$

Whereas the consumption of an IRP is given by

$$
\begin{aligned}
q_{l}^{I R P} & =\left(\frac{\beta}{\gamma} \frac{s}{n} \varepsilon_{l}\right)^{1 / a} \\
q_{l}^{I R P} & =\left(\frac{\beta}{\gamma} \frac{s}{n} \varepsilon_{h}\right)^{1 / a} .
\end{aligned}
$$

The utility under an MSP follows from 45 and 47, which, after some restructuring, is

$$
E U^{M S P}=n\left(\varepsilon_{l} \pi_{l}+\varepsilon_{h} \pi_{h}\right)^{2}\left[2 \frac{\beta}{\gamma}-\left(\frac{\beta}{\gamma}\right)^{2}\right]
$$

For the utility under an IRP, there follows from 45 and 50

$$
E U^{I R P}=n\left(\varepsilon_{h}^{2} \pi_{h}+\varepsilon_{l}^{2} \pi_{l}\right)\left[2 \frac{\beta}{\gamma}-\left(\frac{\beta}{\gamma}\right)^{2}\right] .
$$

The hypothesis is $E U^{I R P}>E U^{M S P}$, which, given 52 and 53 , reduces to

$$
\left(\varepsilon_{h}^{2} \pi_{h}+\varepsilon_{l}^{2} \pi_{l}\right)>\left(\varepsilon_{l} \pi_{l}+\varepsilon_{h} \pi_{h}\right)^{2}
$$

which is true under the assumptions made about $\varepsilon_{l}$ and $\varepsilon_{h}$. q.e.d. 


\section{References}

Altermatt, L. (2017). Inside money, investment, and unconventional monetary policy. university of zurich. Technical report, Department of Economics Working Paper.

Aoki, K. (2003). On the optimal monetary policy response to noisy indicators. Journal of Monetary Economics, 50(3):501-523.

Aoki, K. (2006). Optimal commitment policy under noisy information. Journal of Economic Dynamics and Control, 30(1):81-109.

Berentsen, A., Camera, G., and Waller, C. (2007). Money, credit and banking. Journal of Economic Theory, 135(1):171-195.

Berentsen, A. and Waller, C. (2011). Price-level targeting and stabilization policy. Journal of Money, Credit and Banking, 43(s2):559-580.

Cecchetti, S. (2000). Making monetary policy: Objectives and rules. Oxford Review of Economic Policy, 16(4):43-59.

Eggertsson, G. B. et al. (2003). Zero bound on interest rates and optimal monetary policy. Brookings Papers on Economic Activity, 2003(1):139-233.

Eusepi, S. and Preston, B. (2018). The science of monetary policy: An imperfect knowledge perspective. Journal of Economic Literature, 56(1):3-59.

Friedman, B. M. (1990). Targets and instruments of monetary policy. Handbook of Monetary Economics, 2:1185-1230.

Head, A., Qiu, J., et al. (2008). Elastic money, inflation and interest rate policy. Technical report, Working Paper, Queens University.

Lagos, R. and Wright, R. (2005). A unified framework for monetary theory and policy analysis. Journal of Political Economy, 113(3):463-484.

Poole, W. (1970). Optimal choice of monetary policy instruments in a simple stochastic macro model. The Quarterly Journal of Economics, 84(2):197-216.

Rocheteau, G. and Wright, R. (2005). Money in search equilibrium, in competitive equilibrium, and in competitive search equilibrium. Econometrica, 73(1):175-202. 
Rocheteau, G., Wright, R., and Xiao, S. X. (2016). Open market operations. Technical report, Working Paper, Wisconsin.

Sack, B. and Wieland, V. (2000). Interest-rate smoothing and optimal monetary policy: a review of recent empirical evidence. Journal of Economics and Business, 52(1-2):205-228.

Sargent, T. J. and Wallace, N. (1975). " rational" expectations, the optimal monetary instrument, and the optimal money supply rule. Journal of Political economy, 83(2):241-254.

Woodford, M. (2010). Optimal monetary stabilization policy. In Handbook of Monetary Economics, volume 3, pages 723-828. Elsevier.

Woodford, M. (2011). Interest and prices: Foundations of a theory of monetary policy. Princeton University Press. 